Article

\title{
Microwave Assisted Novel Efficient Pd-free Catalyst for Suzuki C-C Coupling Reaction
}

\author{
Ghalia Alzhrani ${ }^{1}$, Nesreen S. Ahmed ${ }^{3}$, Elham S. Azam ${ }^{1}$ and Mohamed Mokhtar 1,2* \\ ${ }^{1}$ Chemistry Department, Faculty of Science, King Abdulaziz University, Jeddah 21589, Saudi Arabia \\ ${ }^{2}$ Physical Chemistry Department, National Research Centre, El Buhouth St., Dokki, Cairo 12622, Egypt \\ ${ }^{3}$ Medicinal Chemistry Department, National Research Centre, El Buhouth St., Dokki, Cairo 12622, Egypt \\ * Correspondence: mmokhtar2000@yahoo.com or mmoustafa@kau.edu.sa (M.M.); Tel.: +96-650-055-8045
}

\begin{abstract}
Suzuki cross-coupling reaction has developed one of the furthermost effectual approaches for the synthesis of biaryls or substituted aromatic moieties from aryl halides and arylboronic acids with a palladium-catalyst in the past two era's. Herein, Pd-free layered double hydroxide containing nickel catalysts were prepared by co-precipitation method under ultrasonic irradiation and $\mathrm{N}_{2}$ atmosphere with different molar ratios of $\mathrm{Ni}: \mathrm{Mg}: \mathrm{Al}$ and coded as (1NiLDHs-Dr), (1.5NiLDHs-Dr) and (2NiLDHs-Dr). A series of reduced catalysts under $5 \% \mathrm{H}_{2} / \mathrm{N}_{2}$ at different temperatures were coded as 1NiLDHs-R200, 1.5NiLDHs-R200 and 2NiLDHs-R200. As-synthesized 2NiLDHs-Dr was the superlative catalyst when coupling different aryl halides with different boronic acids derivatives. Deep investigation of all catalysts was done using different techniques such as inductively coupled plasma optical emission spectroscopy (ICP-OES), $\mathrm{x}$-ray photoelectron spectroscopy (XPS), powder x-ray diffraction (XRD), thermogravimetric analyses (TGA), Fourier transfer infrared (FTIR), scanning electron microscope (SEM) connected with energy dispersive $x$ ray (EDX) and $\mathrm{N}_{2}$-physisorption at $-196{ }^{\circ} \mathrm{C}$. The results attained verified that $\mathrm{a}-\mathrm{Ni}(\mathrm{OH})_{2}$ was fashioned for 2NiLDHs-Dr catalyst and the enclosure of nickel ions in the cationic sheet of layered structure were responsible for the fascinating catalytic efficacy rather than the basic nature of material. The Ni-containing LDHs catalysts encourage forthcoming studies in Pd-free catalyzed CC coupling reactions.
\end{abstract}

Keywords: Suzuki coupling reaction; Layered double hydroxides; Solid base catalyst, Microwave irradiation.

\section{Introduction}

Suzuki-Miyaura coupling reaction includes coupling an aromatic hydrocarbon or ethenyl boronic acid or boronic ester with aryl or ethenyl halides in the presence of a base (Scheme 1). It is generally carried out at temperatures range of $60-120^{\circ} \mathrm{C}$ with generally excellent yield results when palladium was used in homogenous catalyzed system which is considered the most powerful and most applicable method for carbon - carbon bond formation. It is the backbone for biaryl and heterobiaryl compouds that are important in natural products, dyes, liquid crystals and dendrimers formation, ligands for catalysis and organic light-emitting polymers synthesis, pharmaceuticals and agrochemicals industries.

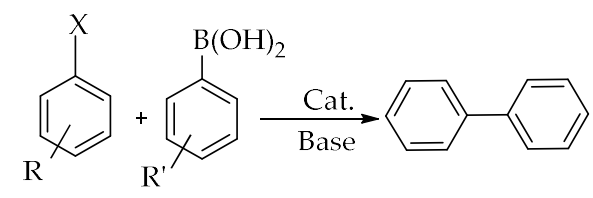

Scheme 1. General scheme for Suzuki-Miyaura reaction. 
Furthermore, homogeneous catalysis is not preferably used due to the lack of reuse, the problem catalyst recycling leads to loss of noble metals and metals residual in the products and the purification becomes necessarily required especially when it use in pharmaceutical production. Therefore, there is needing to remove residual metals impurities in products and losing the expensive metals by palladium substitution, partially or totally, with cheap metals like non-noble metals. Also, heterogeneous catalysis is a promising option because it offers several advantages like high catalyst stability, the catalyst is easily removal from mixture of the reaction by simple filtration and reusing the catalyst many times with a frequent activity loss minimum.

Different types of transition metals were used to catalyze Suzuki coupling reaction. Volpe and co-workers [1] reported that a series of ceria catalysts used in Suzuki-Miyaura cross-coupling reaction between 4-iodotoluene and phenylboronic acid. The reaction was carried out at $150{ }^{\circ} \mathrm{C}$, under $\mathrm{N}_{2}$ atmosphere and DMF as the solvent which resulting in corresponding biphenyl in high selectivity percentage (Table 1, Entry 1).

Gold nanoparticles - graphene hybrids have been prepared by Li and his group [2]. They reported that the $\mathrm{Au} /$ graphene catalyst can act as efficient catalysts for the Suzuki reaction in water under aerobic conditions. They found the catalytic activity of gold nanoparticles - graphene hybrids which expressed as a value of selectivity was influenced by the size of the gold nanoparticles (Table 1, Entries 2,3).

Kim and co-workers [3] demonstrated that the Pt single atoms on thiolated multi-walled carbon nanotubes (Pt-S-MWNT) has a remarkably high activity and recyclability for the ligand-free Suzuki coupling reaction. Pt-S-MWNT showed a high activity in coupling process of iodoarene with methyl phenylboronic acid in presence of $\mathrm{Cs}_{2} \mathrm{CO}_{3}$ as base at $70{ }^{\circ} \mathrm{C}$ after $24 \mathrm{~h}$ (Table 1, Entry 4).

In 2008, Mao and co-workers developed an effective catalytic system from copper powder with $\mathrm{K}_{2} \mathrm{CO}_{3}$ as the base that was extremely effective catalyst for Suzukie Miyaura coupling reaction performed in polyethylene glycol 400 (PEG-400), which afforded almost quantitative coupling products of aryl iodides [4]. In the case of aryl bromides or chlorides, the coupling products could be obtained with moderate to good yields when using iodine as additive (Table 1, Entry 5).

Lipshutz and co-workers have used nickel on charcoal (Ni/C) [5] that worked as an effective heterogeneous catalyst for coupling chloroarenes and phenylboronic acids in presence triphenylphosphine ligand (PPh3) to give biphenyl products in good yields (Table 1, Entry 6). It was noticed little nickel was released from the charcoal during the coupling process, as established by ICP experiments. In 2008, the researchers group have reported a nickel-on-graphite $\left(\mathrm{Ni} / \mathrm{C}_{\mathrm{g}}\right)[6]$, as a safe and especially inexpensive material, which used to catalyze cross couplings with various boronic acids and aryl halides by bath heating or under Microwave (MW) conditions (Table 1, Entries 7, 8).

Wang and co-workers [7] have developed an efficient, simple and economic catalyst system for the Suzuki-Miyaura reaction of aryl iodides and bromides with aryl boronic acid without the need of phosphine ligands by using nickel-metal colloid supported on TBAB (tetra-n-butylammonium bromide). $\mathrm{Ni}^{(0)} / \mathrm{TBAB}$ exhibited high activity for aryl bromides and iodides. In case of less reactive aryl chlorides, the phosphine ligand was required for more efficient reaction (Table 1, Entry 9).

In 2017, Willand and co-workers [8] improved procedure in the Suzuki Miyaura cross coupling reaction between $\mathrm{N}-\mathrm{BOC}$ protected 3-iodoazetidine and a large variety of heteroaryl and arylboronic acids. The reaction was catalyzed by Nickel in the presence of NaHMDS as strong base and is promoted by microwave heating (Table 1, Entry 10). Furthermore, the N-protected azetidine can be further functionalized after deprotection.

Guo and his co-workers [9] studied the effect of elevated pressure in the liquid phase on the Suzuki-Miyaura cross-coupling of aryl halides and aryl boronic acids using cheaper Fe(III), Co(II), and $\mathrm{Ni}(\mathrm{II})$ metal salts as catalysts. The yields were improved (Table 1, Entries 11-13) at $15 \mathrm{kbar}$ but this procedure was disgraced with high loading of catalysts.

In 2003, Leadbeater and Marco [10] claimed that the Suzuki Miyaura coupling of boronic acids and aryl halides is possible without the need for a transition-metal catalyst. This methodology offers significant advantages since the use of transition metals leads to the generation of waste and has a number of hazards associated with it especially if this methodology used the water as solvent. The 
methodology was applicable to a wide range of aryl bromide substrates (Table 1, Entry 14), with good yields being obtained in the reaction with phenylboronic acid in presence of tetrabutylammonium bromide (TBAB) and $\mathrm{Na}_{2} \mathrm{CO}_{3}$ as base. The methodology has been proven that the reaction was indeed metal-free by using new glassware, apparatus, and reagents and analyzed the entire crude product mixture for palladium and other metals content. They found that there was no palladium down to below $0.1 \mathrm{ppm}$. Also, they found by using inductively coupled plasma atomic absorption (ICP-AA) spectroscopy none of the other metals were present in the product mixture in concentrations above the level of detection of the apparatus of $0.5-1 \mathrm{ppm}$.

After one year, Leadbeater and co-workers [11] reported that when the Suzuki reaction is performed without the addition of a transition-metal catalyst but using commercially sodium carbonate as a base, palladium contaminants down to a level of $0.05 \mathrm{ppm}$ are responsible for the formation of the biaryls (Table 1, Entries 15-17).

In order to investigate the possibility of catalyst-free Suzuki reaction, Yan and his co-workers reported in 2006 a novel and efficient method for coupling reaction of sodium tetraphenylborate with iodonium salts in acidic water [12]. This method was simple, mild, high-yielding, and more environmentally benign (Table 1, Entry 18). In the same year, Yan and his co-workers deeply investigated and they came to develop a greener procedure for catalyst- and solvent-free Suzuki coupling reaction of sodium tetraphenylborate with hypervalent iodonium salts that was carried out under microwave irradiation in the absence of a base [13]. This procedure provided a fast, simple and efficient method for preparation of biaryls with mild reaction conditions and good yields were obtained (Table 1, Entry 19).

Table 1. Survey on different catalysts for Suzuki coupling reaction.

\begin{tabular}{|c|c|c|c|c|c|c|c|c|}
\hline & Aryl halide & $\begin{array}{l}\text { Boronic acid } \\
\text { direvative }\end{array}$ & Cat. & Base & Solvent & Conditions & $\mathrm{t}(\mathrm{h})$ & Yield (\%) \\
\hline 1 & & & $\mathrm{HSA}-\mathrm{CeO}_{2}$ & $\mathrm{~K}_{2} \mathrm{CO}_{3}$ & DMF & $\begin{array}{l}150^{\circ} \mathrm{C} \\
0.1 \mathrm{MPa}\end{array}$ & 3 & $\begin{array}{l}89 \\
\text { Selectivity }\end{array}$ \\
\hline 2 & & & $\begin{array}{l}\text { Au-graphene } \\
(2-3 \mathrm{~nm})\end{array}$ & $\mathrm{NaOH}$ & $\mathrm{H}_{2} \mathrm{O}$ & $100^{\circ} \mathrm{C}$ & 4 & $\begin{array}{l}85.8 \\
\text { Selectivity }\end{array}$ \\
\hline 3 & & & $\begin{array}{l}\text { Au-graphene } \\
(7.5 \mathrm{~nm})\end{array}$ & $\mathrm{NaOH}$ & $\mathrm{H}_{2} \mathrm{O}$ & $100^{\circ} \mathrm{C}$ & 4 & $\begin{array}{l}11.2 \\
\text { Selectivity }\end{array}$ \\
\hline 4 & & & Pt-S-MWNT & $\mathrm{Cs}_{2} \mathrm{CO}_{3}$ & THF & $70^{\circ} \mathrm{C}$ & 24 & 99.5 \\
\hline 5 & & & $\mathrm{Cu}^{(0)}$ & $\mathrm{K}_{2} \mathrm{CO}_{3}$ & PEG-400 & $110^{\circ} \mathrm{C}$ & 12 & 99 \\
\hline 6 & & & $\mathrm{Ni} / \mathrm{C}$ & $\begin{array}{l}\mathrm{K}_{3} \mathrm{PO}_{4} \\
\mathrm{LiBr}\end{array}$ & Dioxane & $135^{\circ} \mathrm{C}$ & 18 & 92 \\
\hline 7 & & & $\mathrm{Ni} / \mathrm{C}_{\mathrm{g}}$ & $\begin{array}{l}\mathrm{K}_{3} \mathrm{PO}_{4} \\
\mathrm{LiBr}\end{array}$ & Dioxane & $135^{\circ} \mathrm{C}$ & 9 & 87 \\
\hline 8 & & & $\mathrm{Ni} / \mathrm{C}_{\mathrm{g}}$ & $\begin{array}{l}\mathrm{K}_{3} \mathrm{PO}_{4} \\
\mathrm{LiBr}\end{array}$ & Dioxane & $\begin{array}{l}\mathrm{MW}, \\
180^{\circ} \mathrm{C}\end{array}$ & $\begin{array}{l}42 \\
\min \end{array}$ & 87 \\
\hline 9 & & & $\mathrm{Ni}^{(0)} / \mathrm{TBAB}$ & $\mathrm{Na}_{2} \mathrm{CO}_{3}$ & $\mathrm{EtOH}$ & $80^{\circ} \mathrm{C}$ & 6 & 95 \\
\hline
\end{tabular}


4 of 22

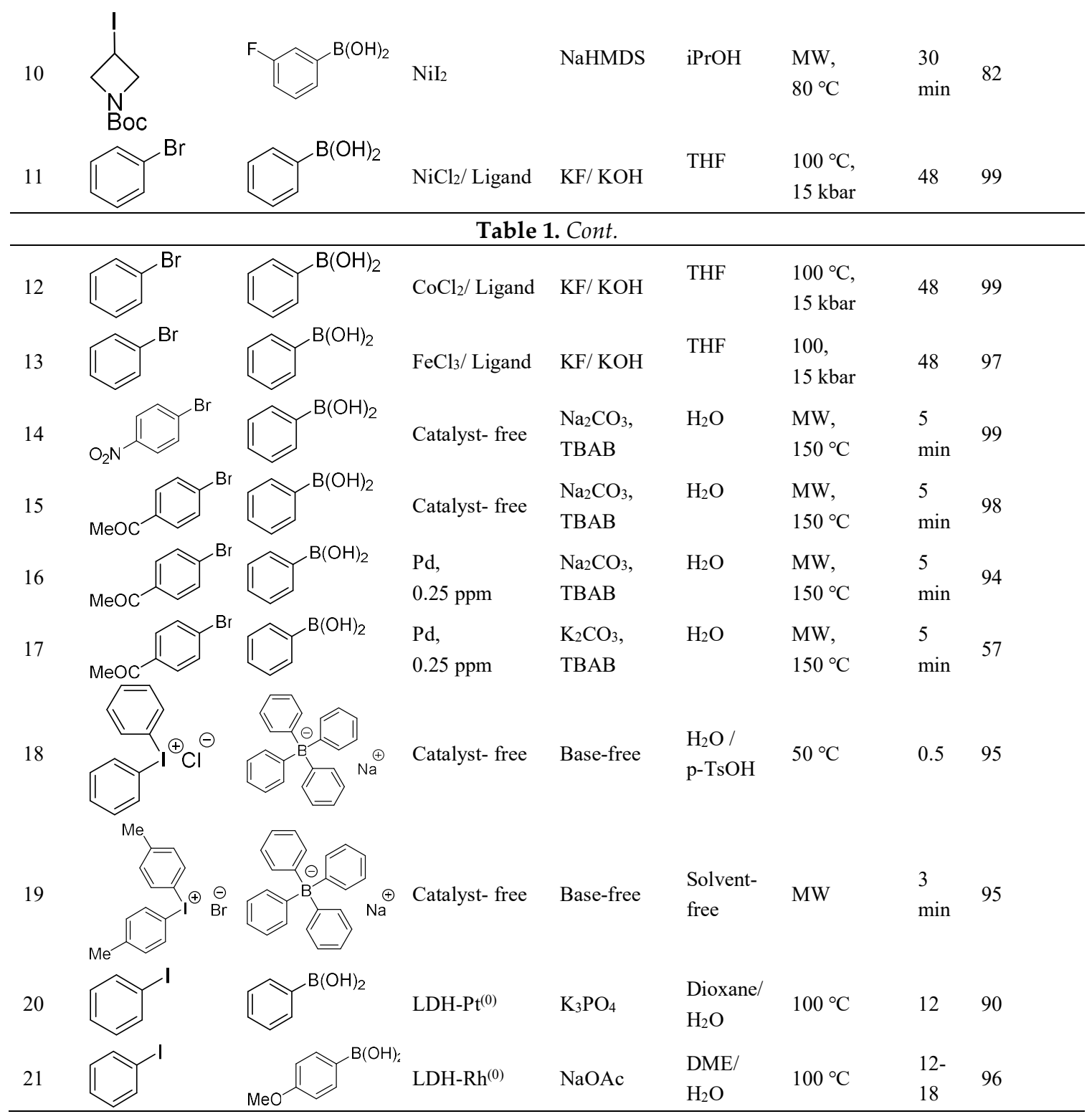

In period of ten years, a class of anionic clay is called layered double hydroxides (LDHs) or hydrotalcite (HTs) has attracted considerable interest from industrial and academic fields. LDHs are lamellar mixed hydroxides which have structured-layer and have hydroxide and carbonate ions intercalated in common, which usually restrict C-C coupling reactions. Mixed metal oxide could be obtained from these materials when subjected to thermal treatment and they can become a promising candidate for C-C coupling reactions. Furthermore, the separation is easier than before after the end of reaction, that way makes LDHs an important alternative to homogeneous catalysts because of the potential of its recycling [14]. Mg-Al-layered double hydroxide (LDH) has been used successfully as solid support for Suzuki reaction by Choudary and his co-workers. In the absence of ligand, LDH$\mathrm{Pt}^{(0)}[15]$ and $\mathrm{LDH}-\mathrm{Rh}^{(0)}$ [16] catalysts were prepared and utilized for Suzuki coupling of different aryl halides with a large number of arylboronic acids to give the corresponding biaryls in good to excellent yields (Table 1, Entries 20, 21). Carbon - carbon bond formation was investigated by our group using LDHs alone [17, 18] and supported on other materials such carbon nanotubes [19] and graphene oxides [20].

In this study we will present a simple generic protocol for the preparation of NiLDHs for Suzuki -Miyaura reaction. This has proven successful for biaryl products derived from different aryl halides 
and aryl boronic acids using microwave irradiation methodology. Herein we report the results of our investigation which showed that NiLDHs behave as a very efficient catalyst of the Suzuki reaction in a Pd and ligands-free.

Extensive survey about LDHs-containing nickel using as catalyst in Suzuki coupling reaction in absence of ligands has been done and to our knowledge no publications have been found.

\section{Results}

\subsection{Elemental Chemical analysis (ICP-OES)}

ICP analysis of NiLDHs-Dr samples was done to determine their chemical composition. The analysis showed that the MII/MIII molar ratio in the solid form of 1NiLDHs-Dr, 1.5NiLDHs-Dr and 2NiLDHs-Dr were 2.11, 2.17 and 2.28 respectively (Figure 1, Table 2). The molar ratios of NiLDHsDr samples indicate the efficiency of the preparation method because they are almost equal to the minimal molar composition of the as-synthesized $\mathrm{Ni}+\mathrm{Mg} / \mathrm{Al}$ molar ratio of 2 in the precipitate that prove also that LDHs phases are pure due to their stoichiometries formation is in the range $0.20<x<$ 0.33 , i.e. MII/MIII ratios in the range 2-4 [21].

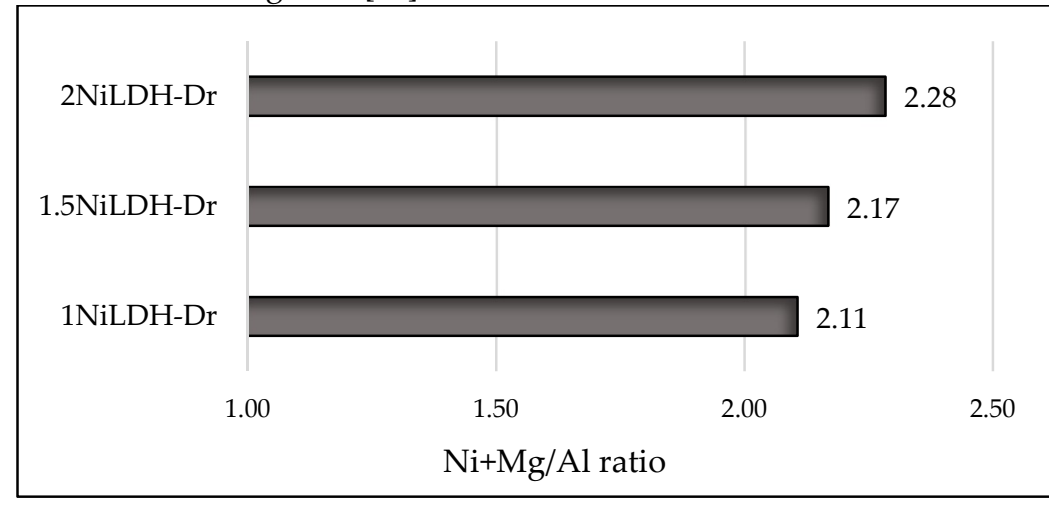

Figure 1. Representative graph for chemical analysis of ratio for NiLDHs-Dr.

\subsection{X-ray photoelectron microscopy (XPS)}

XPS investigation was conducted to gain further insight into the location and nature of the $\mathrm{Ni}$ species present in NiLDHs-Dr samples. Deconvoluted Ni 2p3/2 X-ray photoelectron spectra for 1NiLDHs-Dr, 1.5NiLDHs-Dr and 2NiLDHs-Dr samples are shown in Figure 2. All XPS spectra of samples have the same Ni species nature. Figure 2 shows the Ni 2p3/2 XPS spectrum from $\mathrm{Ni}(\mathrm{OH})_{2}$ with the two obvious satellite intensities fit by broad peaks with binding energy at main line 852.0 $\mathrm{eV}$ (Table 2). The peaks have been deconvoluted into two contributions with binding energies at 855.8 $\mathrm{eV}$ and $861.4 \mathrm{eV}$ respectively [22]. The first peak can be assigned to isolated $\mathrm{Ni}^{2+}$ species. It is interesting to note that the $2 \mathrm{NiLDHs}-\mathrm{Dr}$ sample contained the highest amount of isolated $\mathrm{Ni}^{2+}$ species $(97.7 \%)$. 

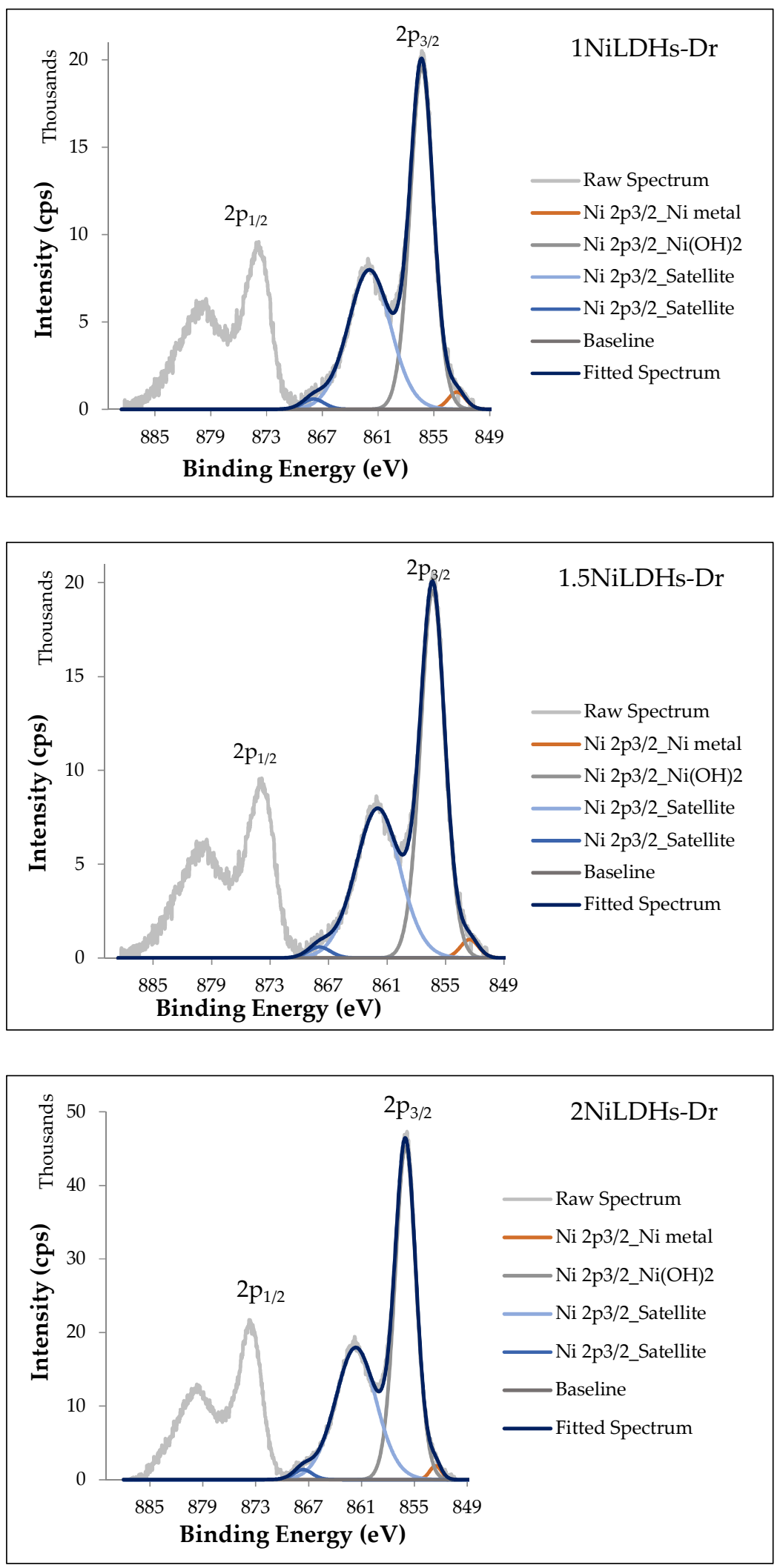

Figure 2. Deconvoluted Ni 2p3/2 XPS spectra for NiLDHs-Dr samples. 
7 of 22

\subsection{Basic properties of NiLDHs-Dr}

The strength of basic sites and their amounts were measured using acid-base titration and the Hammett indicator methods. Since the catalysts are considered have basic properties, the number of moles of basic sites were calculated and it was found in order of 1NiLDHs-Dr > 1.5NiLDHs-Dr > 2NiLDHs-Dr. Where the base strength of 1NiLDHs-Dr, 1.5NiLDHs-Dr and 2NiLDHs-Dr are found in range of $\mathrm{pK}_{\mathrm{BH}+}=11.1-12.7$ (Table 7). There is no change in colors of catalysts filtrate which mean there are no leachable basicity from all the catalysts. The reduction in basic sites upon substitution of $\mathrm{Mg}^{2+}$ ions by $\mathrm{Ni}^{2+}$ ions in the NiLDHs samples could be credited to the departure of Lewis basic sites or formation of new phase structure of $\mathrm{a}-\mathrm{Ni}(\mathrm{OH})_{2}$, which is less basic than brucite $\beta-\mathrm{Ni}(\mathrm{OH})_{2}$ phase [23].

Table 2. Elemental chemical, XPS data and basic properties of NiLDHs-Dr samples.

\begin{tabular}{|c|c|c|c|c|c|}
\hline & \multicolumn{2}{|c|}{$\mathrm{Ni}+\mathrm{Mg} / \mathrm{Al}$} & \multirow{2}{*}{$\begin{array}{c}\text { Basic strength } \\
\mathrm{mmol} / \mathrm{g}\end{array}$} & \multicolumn{2}{|c|}{$\mathrm{Ni}^{2+}$ isolated species sample } \\
\hline & Solution & Soild & & $\begin{array}{l}\text { Binding energy } \\
(\mathrm{eV})\end{array}$ & $\%$ \\
\hline 1NiLDH-Dr & 2.0 & 2.11 & 0.333 & 856.1 & 96.4 \\
\hline 1.5NiLDH-Dr & 2.0 & 2.17 & 0.173 & 855.6 & 96.5 \\
\hline 2NiLDH-Dr & 2.0 & 2.28 & 0.073 & 855.8 & 97.7 \\
\hline
\end{tabular}

\subsection{X-ray diffraction (XRD)}

X-ray diffraction pattern of prepared NiLDHs-Dr are shown in Figure 3. It is sharp high intensity signals at low $2 \theta$ values and weak signals at high $2 \theta$ values. It is signing that LDH structure was successfully attained, where the sample has the three characteristic XRD reflections of LDH. The reflection peaks are presented in Table 3. Full width at half maximum (FWHM) of the most intense peak was used to deduce the size (D) of crystallite/ particle using Debye-Scherrer's equation: $\mathrm{D}=0.9$ $\lambda / \beta \cos \theta$. The crystallite size of different NiLDHs-Dr are 40.67, 50.92 and $67.73 \mathrm{~nm}$ for 1 NiLDHsDr, 1.5NiLDHs-Dr and 2NiLDHs-Dr, respectively. The crystallite sizes of NiLDHs-Dr increase with the increase of $\mathrm{Ni}$ content. Usually, $\mathrm{Ni}$ could be represented either in $\beta-\mathrm{Ni}(\mathrm{OH})_{2}$ (strictly packed brucite type layers in which $\mathrm{Ni}^{2+}$ is in the middle of hydroxyl octahedral structure), and a- $\mathrm{Ni}(\mathrm{OH})_{2}$ (NiLDHs) of foremost attention due to its tunable assembly (oxidation state, interlayer species, interlayer distance) [21, 24]. The obvious growth in the crystallite size and the intensity of diffraction pattern of the layered structure of the 2NiLDHs-Dr (of high Ni content) without substantial shift in the peak position endorse the a-Ni(OH) 2 creation. 


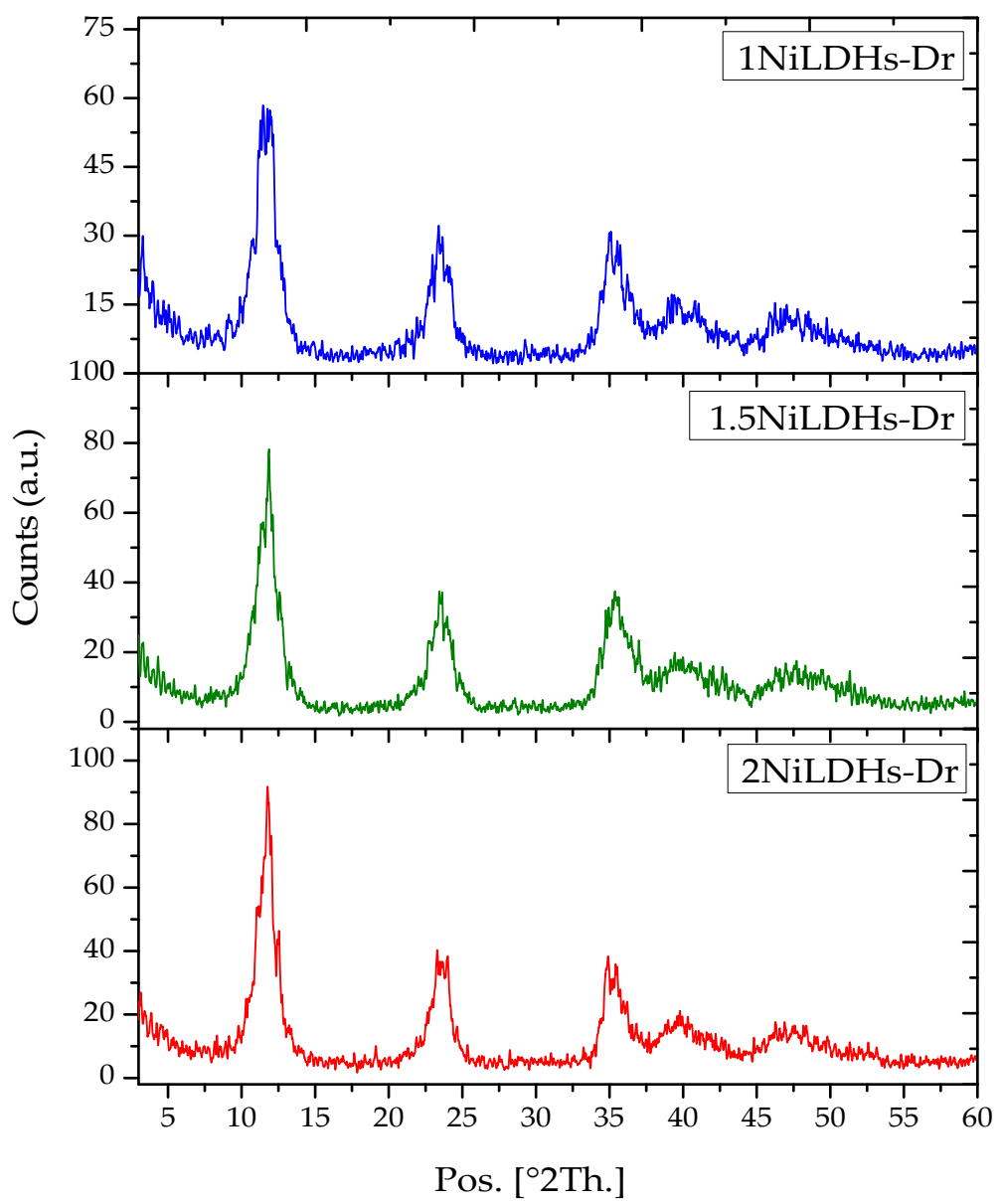

Figure 3. XRD patterns of different NiLDHs-Dr.

Table 3. XRD data for different NiLDHs-Dr

\begin{tabular}{lllllllll}
\hline & 1NiLDHs-Dr & \multicolumn{3}{l}{ 1.5NiLDHs-Dr } & \multicolumn{2}{l}{ 2NiLDHs-Dr } \\
\hline $\begin{array}{l}\text { Pos. } \\
{\left[{ }^{\circ} \text { Th. }\right]}\end{array}$ & $\begin{array}{l}\text { d-spacing } \\
{[\AA]}\end{array}$ & $\begin{array}{l}\text { Crystallite } \\
\text { Size }[\mathrm{nm}]\end{array}$ & $\begin{array}{l}\text { Pos. } \\
{\left[{ }^{\circ} \text { 2Th.] }\right]}\end{array}$ & $\begin{array}{l}\text { d-spacing } \\
{[\AA]}\end{array}$ & $\begin{array}{l}\text { Crystallite } \\
\text { Size }[\mathrm{nm}]\end{array}$ & $\begin{array}{l}\text { Pos. } \\
{\left[{ }^{\circ} \text { 2Th. }\right]}\end{array}$ & $\begin{array}{l}\text { d-spacing } \\
{[\AA]}\end{array}$ & $\begin{array}{l}\text { Crystallite } \\
\text { Size }[\mathrm{nm}]\end{array}$ \\
\hline 11.86 & 7.459 & & 12.08 & 7.326 & & 11.85 & 7.471 & \\
23.91 & 3.722 & 40.67 & 23.47 & 3.791 & 50.92 & 23.47 & 3.791 & 67.73 \\
34.79 & 2.579 & & 35.02 & 2.562 & & 35.44 & 2.533 & \\
\hline
\end{tabular}

\subsection{Thermogravimetric analysis (TGA)}

Thermogravimetric analysis of NiLDHs-Dr are shown in Figure 4. The thermograms of 1NiLDHs-Dr, 1.5NiLDHs-Dr and 2NiLDHs-Dr were analyzed to obtain information about percentage weight loss at different temperatures. The results of these analyses are presented in Table 4. In the $1 \mathrm{NiLDHs}-\mathrm{Dr}$ and $2 \mathrm{NiLDHs}-\mathrm{Dr}$ thermograms, they show five stages of weight loss while 1.5NiLDHs-Dr shows only four stages. The analysis of all stages could be put into three main categories. First range of weight loss $\left(37-110{ }^{\circ} \mathrm{C}\right)$ is attributed to the loss of water molecules at the surface by desorption process and the dehydration of the sample. The second range of weight loss $\left(180-220^{\circ} \mathrm{C}\right)$ which is attributed to loss interlayer water molecules. At the third range of weight loss $\left(250-350{ }^{\circ} \mathrm{C}\right)$ which is attributed to the removal of $\mathrm{OH}^{-}$groups and decarbonation of carbonate anions present in the interlayer space of LDHs that leading to the formation of metal oxides [25]. 


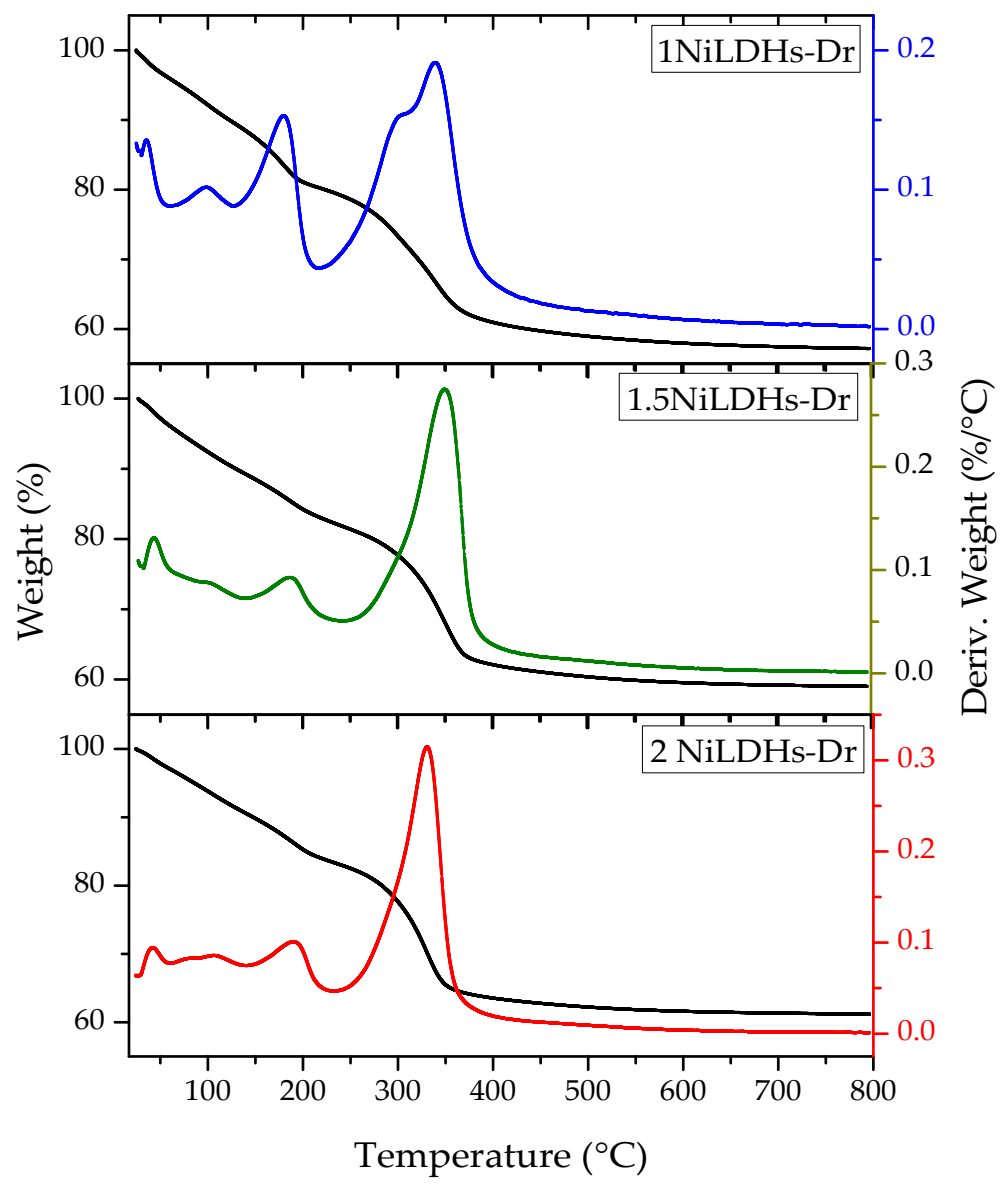

Figure 4. TGA of NiLDHs-Dr.

Table 4. TGA data for NiLDHs-Dr samples.

\begin{tabular}{|c|c|c|c|}
\hline \multirow[b]{2}{*}{ Weight loss steps } & \multicolumn{3}{|c|}{ Temperature ${ }^{\circ} \mathrm{C} / \quad$ Weight loss $\%$} \\
\hline & 1NiLDHs-Dr & 1.5NiLDHs-Dr & 2NiLDHs-Dr \\
\hline 1 & $36.7 / 1.7$ & $44.8 / 2.1$ & $40.6 / 1.3$ \\
\hline 2 & $98.3 / 6$ & $100.6 / 5.5$ & $81.0 / 3.3$ \\
\hline 3 & $180.9 / 8.9$ & 185.2 / 6.8 & $107.0 / 2.2$ \\
\hline 4 & $300.8 / 10.2$ & $349.9 / 17.3$ & 189.9 / 6.9 \\
\hline 5 & 340.2 / 6.6 & & $331.2 / 16.3$ \\
\hline
\end{tabular}

\subsection{Fourier-transform infrared spectroscopy (FT-IR)}

Figure 5 shows the FTIR spectra of 1NiLDHs-Dr, 1.5NiLDHs-Dr and 2NiLDHs-Dr samples which they have similar IR bands. The signal at $3400 \mathrm{~cm}^{-1}$ is the $\mathrm{O}-\mathrm{H}$ stretching band, arising from interlayer water molecules and metal-hydroxyl groups [26]. The small band centered around 1600 $\mathrm{cm}^{-1}$ can be ascribed to the bending vibration of water. Additionally, the band at $1350 \mathrm{~cm}^{-1} \mathrm{can}^{\mathrm{be}}$ assigned to the vibration of interlayer $\mathrm{CO}_{3}{ }^{2-}$ and $\mathrm{NO}_{3}{ }^{-}$anions. The broad peak at $630 \mathrm{~cm}^{-1} \mathrm{can}^{\mathrm{be}}$ assigned to the $\mathrm{M}-\mathrm{O}, \mathrm{O}-\mathrm{M}-\mathrm{O}$, and $\mathrm{M}-\mathrm{O}-\mathrm{M}(\mathrm{M}=\mathrm{Al}, \mathrm{Mg}$ and $\mathrm{Ni}$ ) vibrations. 


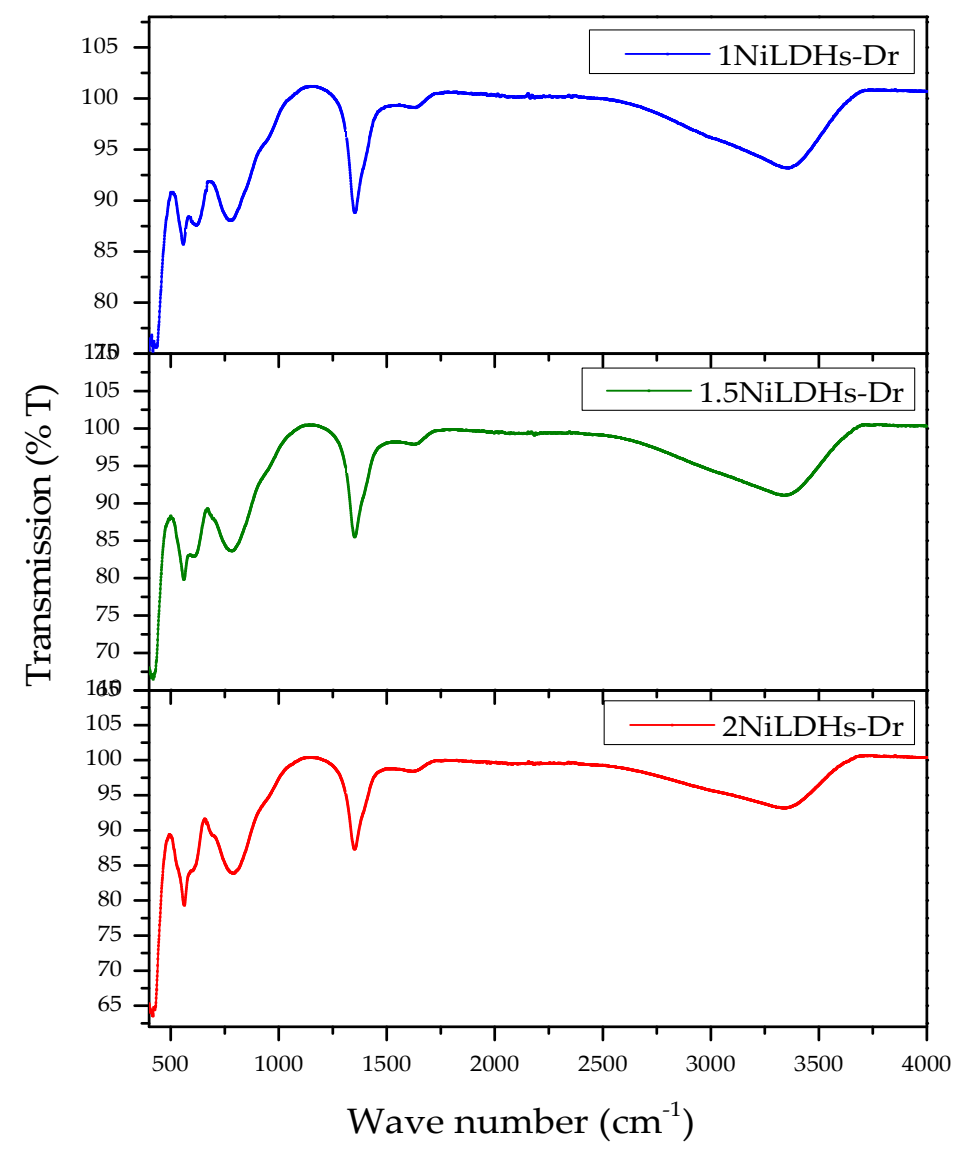

Figure 5. FTIR spectra of NiLDHs-Dr samples.

\section{7. $N_{2}$ physisorption}

Figure 6 show that nitrogen adsorption/desorption isotherm of all samples are type IV according to IUPAC classification [27]. The hysteresis loops in the isotherms indicate the mesoporous nature of NiLDHs-Dr. Hysteresis shapes are attributed to the presence of cylindrical, slit and blind hole pores according to Sing et al [28]. BET surface area for NiLDHs-Dr catalysts have no obvious trend (Table 5). The pore volume and average pore radius decline with growing of Ni content. The formation of a-Ni(OH)2 greatly affect the pore nature by possible aggregation.

Table 5. Textural properties of different NiLDHs-Dr from N2-physisorption.

\begin{tabular}{lcccc}
\hline & BET surface areas $\left(\mathbf{m}^{2} / \mathbf{g}\right)$ & Pore volume $\left(\mathbf{c m}^{3} / \mathbf{g}\right)$ & Av. Pore radius $(\AA)$ & C-constant \\
\hline 1NiLDHs-Dr & 68.28 & 0.14 & 22.71 & 14.27 \\
1.5NiLDHs-Dr & 57.33 & 0.09 & 19.84 & 10.24 \\
2NiLDHs-Dr & 58.03 & 0.08 & 18.97 & 5.95 \\
\hline
\end{tabular}




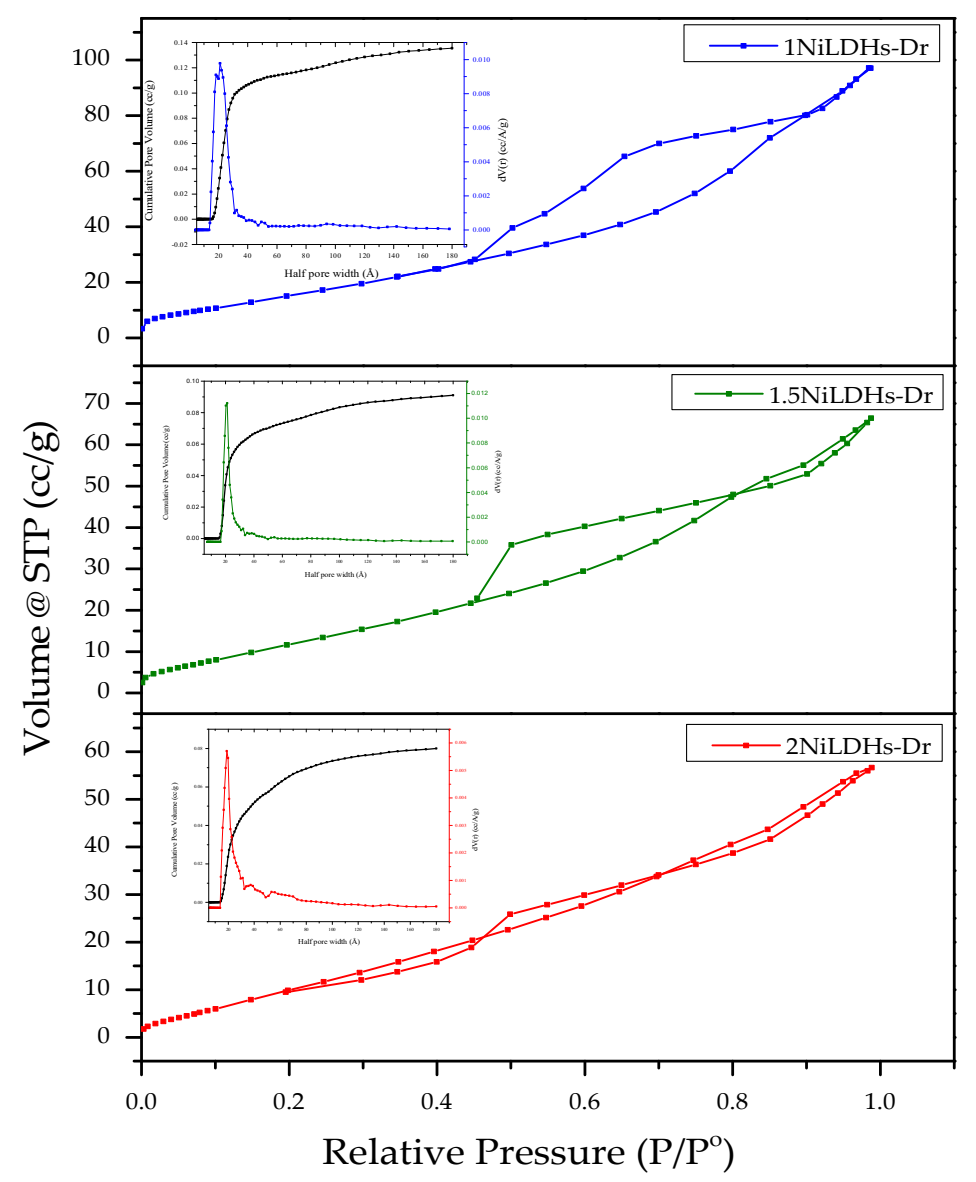

Figure 6. $\mathrm{N}_{2}$ isotherms and Pore size distribution (inset) patterns of different ratio for NiLDHs-Dr.

\subsection{Scanning electron microscopy (SEM-EDX)}

The SEM images of NiLDHs-Dr ravel out the morphology which stacked platelets shape. Figure 7 shows that the layered flakes are clearer in $1 \mathrm{NiLDHs}-\mathrm{Dr}$ than the other $\mathrm{Ni}$ - containing materials. It seems that isomorphic substitution of $\mathrm{Mg}^{2+}$ ions by $\mathrm{Ni}^{2+}$ ions in the cationic sheet and the nucleation of a-Ni(OH $)_{2}$ phase of relatively larger crystallite size as evidenced by XRD data analysis resulted in the distinct thickness progress of the flakes. 2NiLDHs-Dr, of high Ni-content disclosed accumulated gloomy like stacked sheets as a result of $\mathrm{a}-\mathrm{Ni}(\mathrm{OH})_{2}$ foundation. 

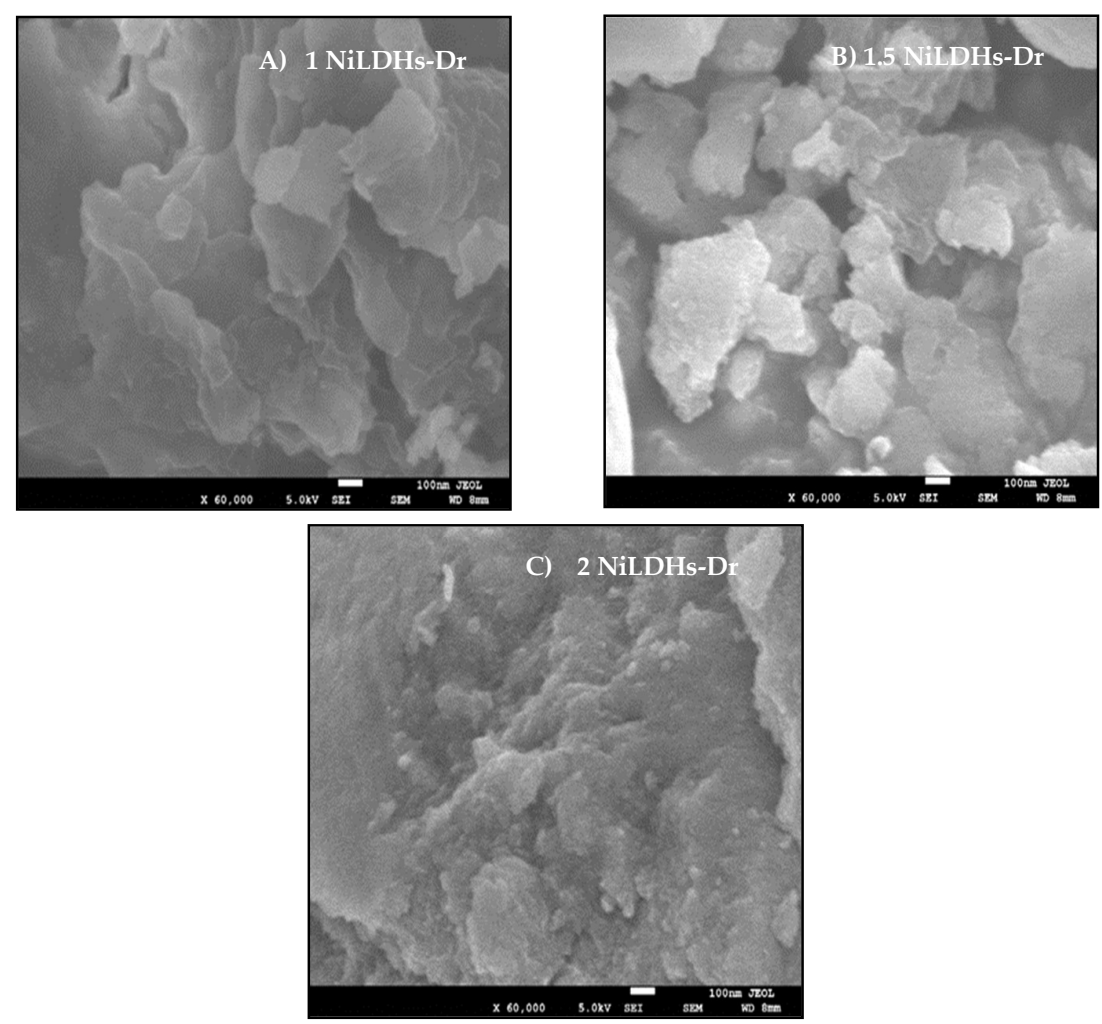

Figure 7. SEM images of all the examined NiLDHs-Dr catalysts.

\subsection{Catalytic activity}

The activity of different forms of NiLDHs catalysts was tested in the Suzuki coupling reaction, which has widely used for the synthesis of biaryl and heterobiaryl compounds [29]. Suzuki coupling reaction of aryl iodides and bromides carried out with high yields mostly in the presence of a good catalyst, base and solvent. The discovery of dedicated tool, catalyst composition, and other reaction conditions to achieve the highest possible product's yield, for the Suzuki coupling reaction should be extensively studied. In the present work Suzuki reaction was performed using different chemical compositions of reduced and dried forms of NiLDHs catalysts in presence of $\mathrm{K}_{3} \mathrm{PO}_{4}$ as base [15] and dioxane - water (5:1) as solvents [30] under microwave irradiation (800W) for 15 min. reaction time. It was found that the Suzuki coupling reaction provided the highest \% product yield $(\sim 35 \%)$ using 2NiLDH-Dr in comparison to 2NiLDHs-R200 and the other forms of 1NiLDHs and 1.5NiLDHs catalysts (Figure 8). 


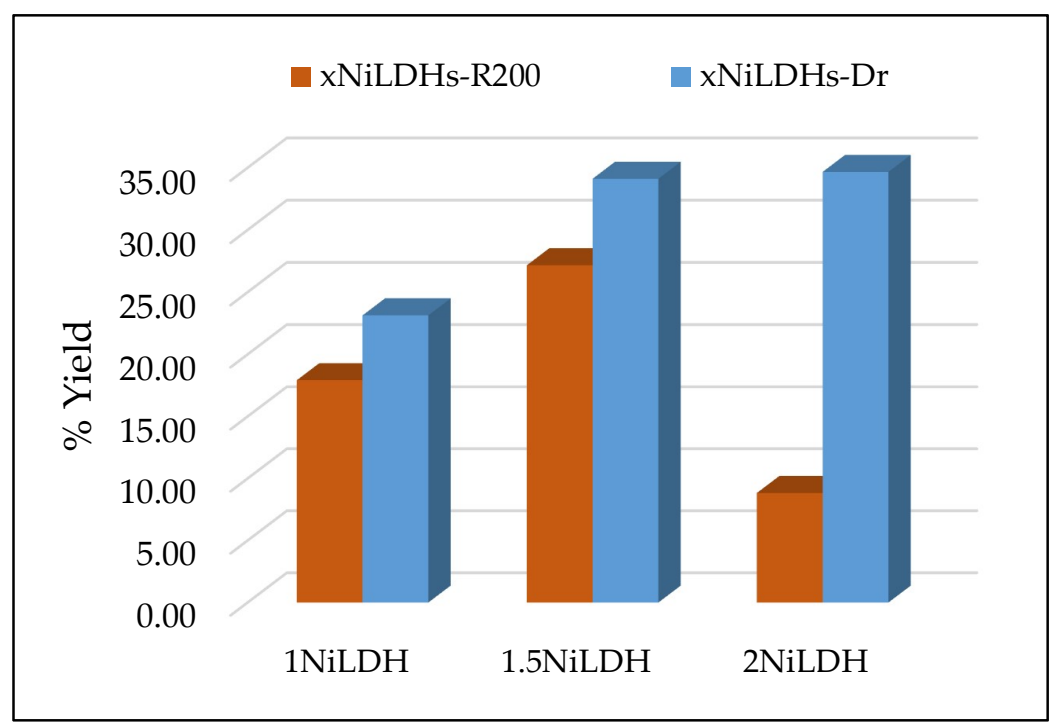

Figure 8. \% product yield utilizing different NiLDHs catalyst composition in reduced and dried forms; reaction conditions: $100 \mathrm{mg}$ of catalyst, $1 \mathrm{mmol}$ of iodobenzene, $1.5 \mathrm{mmol}$ of 4-tolylboronic acid, $2 \mathrm{mmol} \mathrm{K}_{3} \mathrm{PO}_{4}$ and $2 \mathrm{~mL}$ of dioxane/ $\mathrm{H}_{2} \mathrm{O}(5: 1), 800 \mathrm{~W}, 20{ }^{\circ} \mathrm{C}$ and $15 \mathrm{~min}$.

In order to investigate the effect of reduction temperature on the possible improvement of catalytic activity, the excellent catalyst (2NiLDHs-Dr) was reduced at 300 and $450{ }^{\circ} \mathrm{C}$ prior to be used for Suzuki reaction. Figure 9 revealed that the reduced samples over $400{ }^{\circ} \mathrm{C}$ have almost the same activity as 2NiLDHs-Dr when used in coupling of iodobenzene with 4-tolylboronic acid.

Therefore, 2NiLDHs-Dr was the superlative catalyst that selected to explore the optimization conditions for Suzuki coupling reaction. The next parameter has been studied was the reaction time. According to Figure 10, 60 min was perfect time for coupling iodobenzene with 4-tolylboronic acid that gave almost $100 \%$ of 4-methyl biphenyl. Studying the effect of catalyst's mass at 50, 100 and 150 $\mathrm{mg}$ showed that there is no significant difference between 50 and $150 \mathrm{mg}$, they depicted almost the same performance (Figure 11).

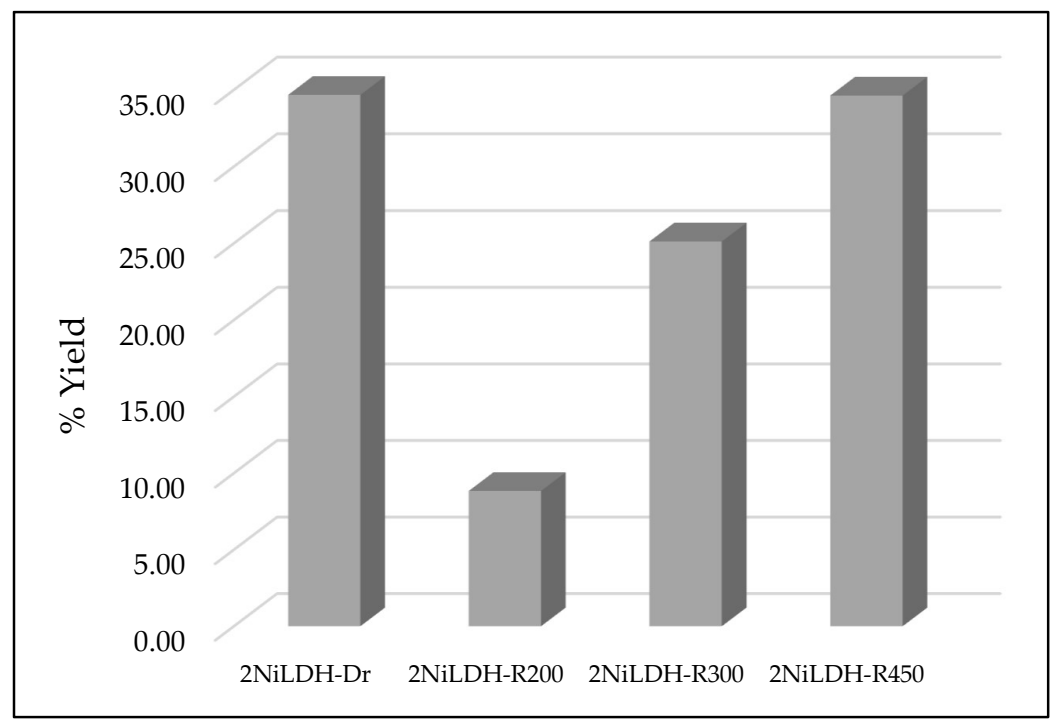

Figure 9. \% product yield utilizing reduced 2NiLDHs catalyst at different temperatures; reaction conditions: $100 \mathrm{mg}$ of catalyst, $1 \mathrm{mmol}$ of iodobenzene, $1.5 \mathrm{mmol}$ of 4-tolylboronic acid, $2 \mathrm{mmol} \mathrm{K}_{3} \mathrm{PO}_{4}$ and $2 \mathrm{~mL}$ of dioxane $/ \mathrm{H}_{2} \mathrm{O}(5: 1), 800 \mathrm{~W}, 200^{\circ} \mathrm{C}$ and $15 \mathrm{~min}$. 


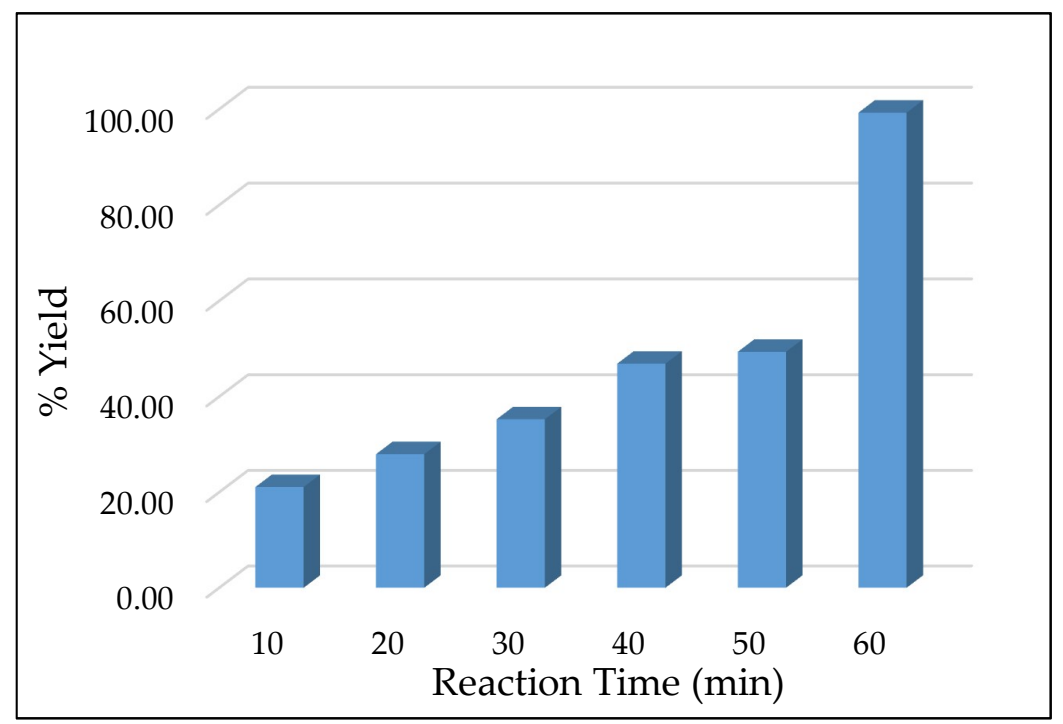

Figure 10. Effect of reaction time on the catalytic performance of 2NiLDHs-Dr; reaction conditions: 50 $\mathrm{mg}$ of catalyst, $1 \mathrm{mmol}$ of iodobenzene, $1.5 \mathrm{mmol}$ of 4 -tolylboronic acid, $2 \mathrm{mmol} \mathrm{K}_{3} \mathrm{PO}_{4}$ and $2 \mathrm{~mL}$ of dioxane $/ \mathrm{H}_{2} \mathrm{O}(5: 1), 800 \mathrm{~W}$ and $200^{\circ} \mathrm{C}$.

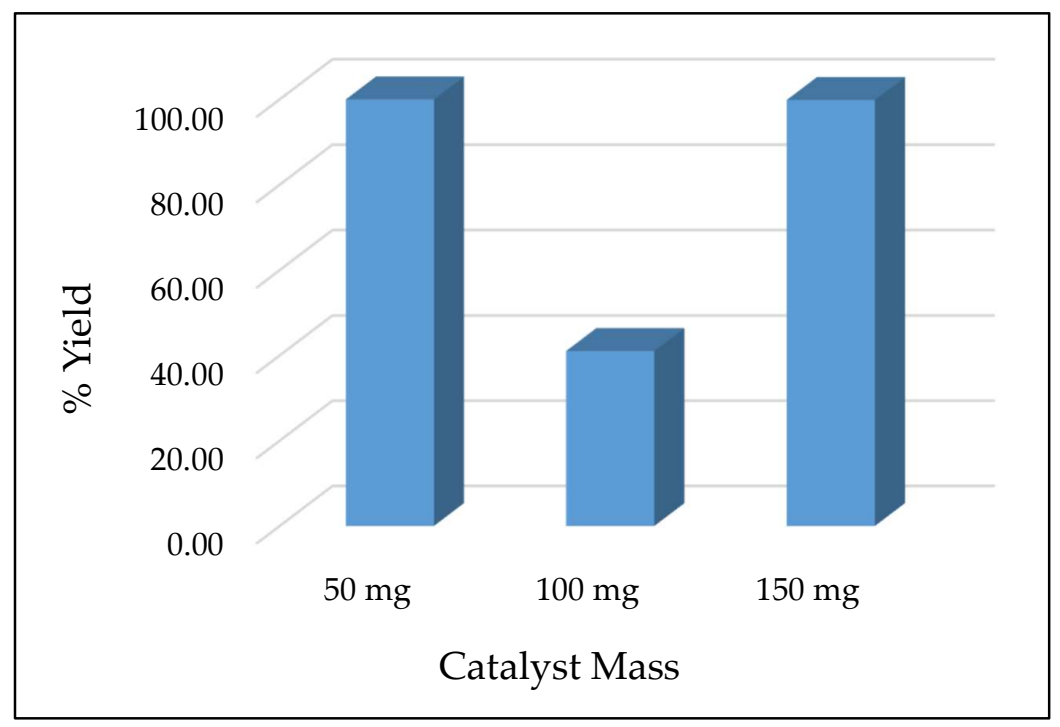

Figure 11. Effect of mass of 2NiLDHs-Dr catalyst on the product's \%yield; reaction conditions: 1 mmol of iodobenzene, $1.5 \mathrm{mmol}$ of 4-tolylboronic acid, $2 \mathrm{mmol} \mathrm{K}_{3} \mathrm{PO}_{4}$ and $2 \mathrm{~mL}$ of dioxane/ $\mathrm{H}_{2} \mathrm{O}(5: 1), 800 \mathrm{~W}$, $200^{\circ} \mathrm{C}$ and $60 \mathrm{~min}$.

Figure 12 and Table 6 show that the 2NiLDHs-Dr catalyst displays a high percentage yield for 4-tolyl boronic acid (entry 1,2 and 3,4), an increase by 6.7 and 2.4-fold when compared to the results obtained for phenyl boronic acid with iodobenzene and bromobenzene, respectively [31]. Opposite trend was noticed with chlorobenzene, \% yield for 4-tolyl boronic acid (entry 5,6) decreased by 1.7fold compared to results obtained for phenyl boronic acid [30,32]. In previous studies, coupling iodobenzene with phenyl boronic acid showed high percentage yield than coupling with 4-tolyl boronic acid [16]. While some studies in literature [15] agreed with our results. In case of bromobenzene, it showed high percentage yield with 4-tolyl boronic acid but Choudary's group [15] showed that phenyl boronic acid has better yield than 4-tolyl boronic acid. Coupling with 4-tolyl boronic acid shows the order $\mathrm{Ar}-\mathrm{I}>\mathrm{Ar}-\mathrm{Br}>\mathrm{Ar}-\mathrm{Cl}$ which agreed with other studies [3, 33, 34]. 
Table 6. Different reactants that were used in Suzuki reaction utilizing 2NiLDHs-Dr catalyst.

\begin{tabular}{|c|c|c|c|c|}
\hline Entry & Aryl halide & Boronic acid & Product & $\%$ Yield \\
\hline 1 & & & & 99.98 \\
\hline 2 & & & & 14.94 \\
\hline 3 & & & & 76.35 \\
\hline 4 & & & & 31.63 \\
\hline 5 & & & & 13.42 \\
\hline 6 & & & & 23.47 \\
\hline
\end{tabular}

Reaction conditions: $50 \mathrm{mg}$ of catalyst, $1 \mathrm{mmol}$ of aryl halide, $1.5 \mathrm{mmol}$ of bronic acid, $2 \mathrm{mmol}$ of $\mathrm{K}_{3} \mathrm{PO}_{4}, 2 \mathrm{~mL}$ of dioxane $/ \mathrm{H}_{2} \mathrm{O}(5: 1)$. Microwave irradiation $=800 \mathrm{~W}, 200{ }^{\circ} \mathrm{C}$; temperature ramped to that stated and held there for $60 \mathrm{~min}$.

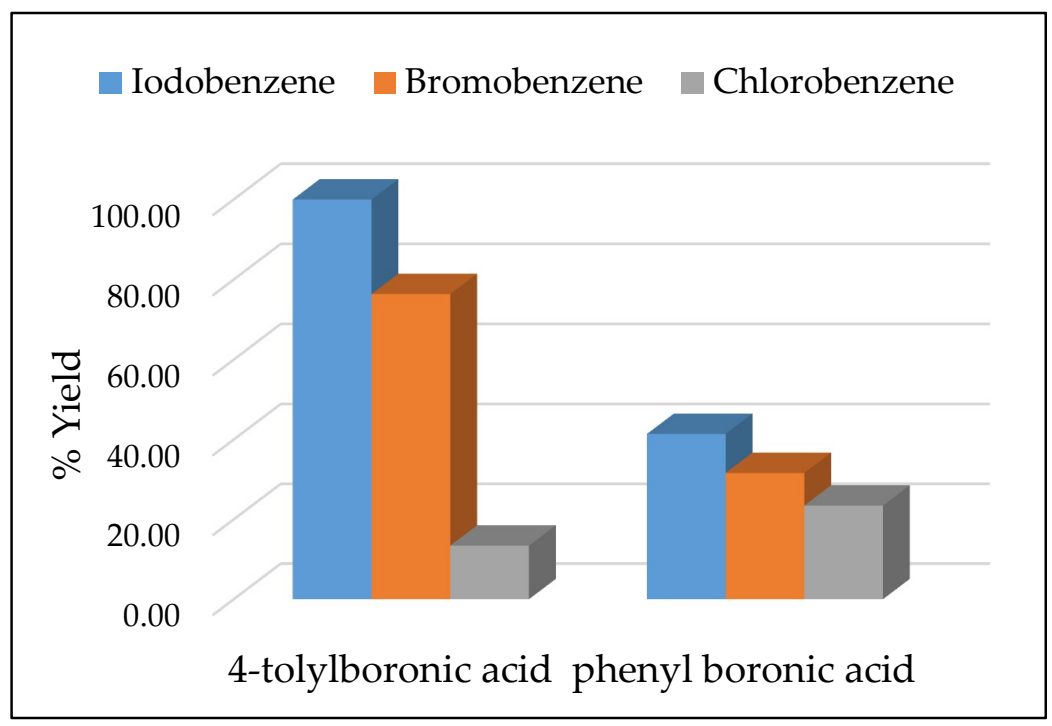

Figure 12. \% yield of different products utilizing 2NiLDHs-Dr; reaction conditions:50 mg of catalyst, $1 \mathrm{mmol}$ of iodobenzene, $1.5 \mathrm{mmol}$ of 4-tolylboronic acid, $1.5 \mathrm{mmol}$ of phenylboronic acid, $2 \mathrm{mmol}$ of $\mathrm{K}_{3} \mathrm{PO}_{4}, 2 \mathrm{~mL}$ of dioxane $/ \mathrm{H}_{2} \mathrm{O}$ (5:1). Microwave irradiation $=800 \mathrm{~W}, 200{ }^{\circ} \mathrm{C}$; temperature ramped to that stated and held there for $60 \mathrm{~min}$.

Snice the Suzuki coupling reaction is important in pharmaceutical industries, obtaining the biphenyl compounds with no residual of $\mathrm{Ni}$, or at least not above the legal limit, which is the case in different metals catalyzed Suzuki reaction, the product mixture of Suzuki reaction was analyzed by 
ICP to test if there is Ni leaching. The results should be agreed with Permitted Daily Exposure (PDE) of $\mathrm{Ni}$ which is $22 \mathrm{ppm}$ parenteral, $6 \mathrm{ppm}$ inhalation and 220 oral [35]. Fortunately, the Ni is not leachable at all $(0 \mathrm{ppm})$ in product mixture which makes 2 NiLDHs-Dr catalyst is a sustainable and promising candidate for Suzuki coupling reaction. It seems that the inclusion of Ni ions in the cationic sheet of layered material fix a comfortable octahedral coordination that resist Ni ions depletion.

\subsection{Reusability of $2 \mathrm{NiLDHs}-\mathrm{Dr}$}

The potential of reusability of a catalyst is an important key in catalytic activity assessment. Therefore, coupling reaction of iodobenzene with 4-methyl tolylboronic acid was repeated four times using the regenerated 2NiLDHs-Dr. The catalyst was removed after the reaction under vacuum filtration using membrane filter $0.45 \mu \mathrm{m}$ to prevent losing of catalyst mass, washed with water to dissolve the remain $\mathrm{K}_{3} \mathrm{PO}_{4}$ then with ethanol to dissolved any organic contaminations after that dried overnight at $80^{\circ} \mathrm{C}$. The recovered catalyst is reused several times under the same optimum conditions that reached to in catalytic activity test section. The drop observed in the catalytic activity of 2NiLDHs-Dr catalyst from the $2^{\text {nd }}$ time of being used which could be attributed to temporary poisoning by organic contaminants, the mass losing of the catalyst and/or to the change in the crystal structure of the catalyst under the operating conditions. Checking for mass losing of 2NiLDHs-Dr, $\mathrm{Ni}$ existence in the filtrate was determined by ICP-OES and it was found that $1.7 \pm 0.05 \mathrm{ppm}\left(2.9 \times 10^{-5}\right.$ mol) from reused $2 \mathrm{NiLDHs}-\mathrm{Dr}$ losing in reaction mixture in every cycle which was not happened with fresh catalyst but agreed with PDE [35]. The Ni leaching after reusing the catalyst could be attributed to washing procedure or to presence the $\mathrm{K}_{3} \mathrm{PO}_{4}$ and tolylboronic acid that might induced the Ni leaching which was proved before by Fang and his co-workers in 2011 in case of Pd leaching [36].

FT-IR spectrum proved presence of contaminated organic moieties that adsorbed on surface of reused 2NiLDHs-Dr (Figure 13) where the absorption band at $1647 \mathrm{~cm}-1$ indicated to $\mathrm{C}=\mathrm{C}$ of benzene ring. Also, FT-IR showed that the crystal structure has been changed by the appeared band at 3642 $\mathrm{cm}-1$ that indicated to $\mathrm{OH}$ stretching of $\mathrm{Ni}(\mathrm{OH}) 2$ and by disappeared band at $1356 \mathrm{~cm}-1$ and $788 \mathrm{~cm}-$ 1 which indicated to $\mathrm{CO} 32-$ and $\mathrm{M}-\mathrm{O}-\mathrm{M}$, respectively. The decay in catalytic activity indicate that the activity of this catalyst attributed to Ni more than to basicity nature of the catalyst.

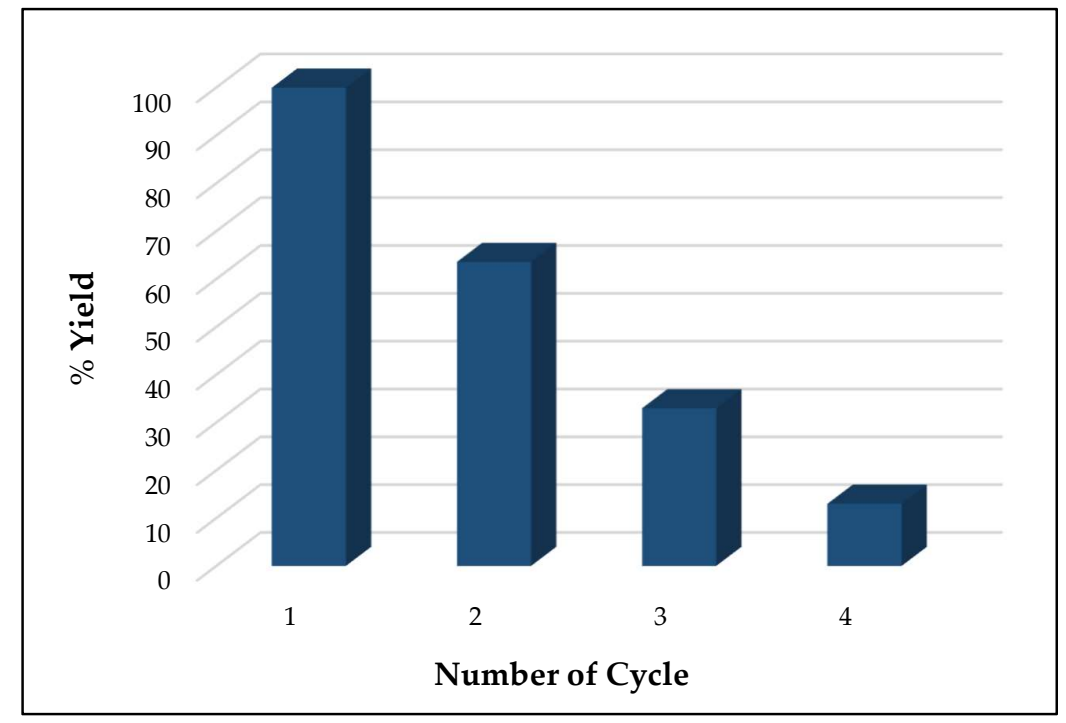

Figure 12. Reusability of 2NiLDHs-Dr catalyst, reaction conditions in every cycle: $1 \mathrm{mmol}$ of iodobenzene, $1.5 \mathrm{mmol}$ of 4-tolylboronic acid, $2 \mathrm{mmol} \mathrm{K}_{3} \mathrm{PO}_{4}$ and $2 \mathrm{~mL}$ of dioxane/ $\mathrm{H}_{2} \mathrm{O}$ (5:1), 800W, $200^{\circ} \mathrm{C}$ and $60 \mathrm{~min}$. 
17 of 22

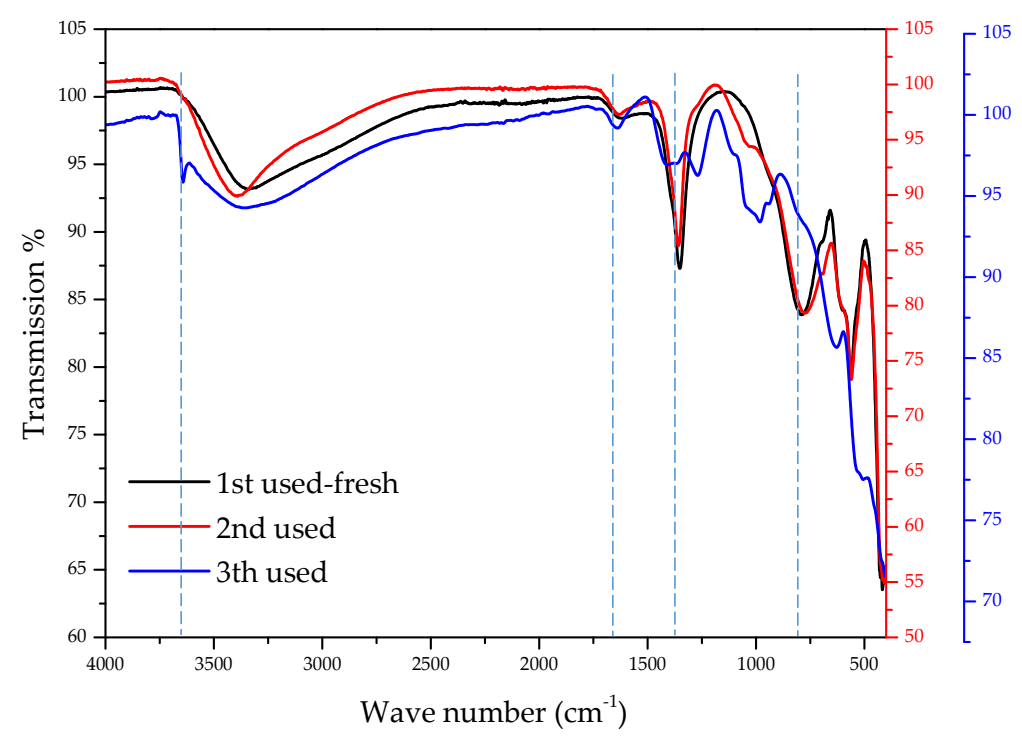

Figure 13. FT-IR spectra of fresh and reused 2NiLDHs-Dr catalyst.

\section{Experimental Details}

\subsection{Materials}

$\mathrm{Al}\left(\mathrm{NO}_{3}\right)_{3} .9 \mathrm{H}_{2} \mathrm{O}, \mathrm{Ni}\left(\mathrm{NO}_{3}\right)_{2} .6 \mathrm{H}_{2} \mathrm{O}$ and Iodobenzene were purchased from Fluka. $\mathrm{Mg}\left(\mathrm{NO}_{3}\right)_{2} .6 \mathrm{H}_{2} \mathrm{O}$ was purchased from Koch-Light. Chlorobenzene and $\mathrm{Na}_{2} \mathrm{CO}_{3}$ were purchased from $\mathrm{BDH}$, England. Bromobenzene was purchased from $\mathrm{MCIB}$, USA. $\mathrm{NaOH}$ was purchased from Riedel-de Haën. 4Tolylboronic acid, 97\% was purchased from Acros Organics. Pre-coated TLC sheets silica gel 60 F254 from Merck to monitor the reaction process.

\subsection{Preparation of $\mathrm{NiLDHs}$}

NiLDHs with molar ratio 1:1:1, 1:0.5:1.5 and 1:0:2 of Al: Mg: Ni (with constant molar ratio of $\mathrm{M}^{(\mathrm{II})} / \mathrm{M}^{(\mathrm{III})}$ by 2:1) synthesized using co-precipitation method. At $50{ }^{\circ} \mathrm{C}$ in sonicated bath, mixture of $\mathrm{Al}\left(\mathrm{NO}_{3}\right)_{3}, \mathrm{Mg}\left(\mathrm{NO}_{3}\right)_{2}$ and $\mathrm{Ni}\left(\mathrm{NO}_{3}\right)_{2}$ as a SLOUTION A was added simultaneously with a mixture of $1.0 \mathrm{~mol}$ of $\mathrm{NaOH}$ and $0.5 \mathrm{~mol}$ of $\mathrm{Na}_{2} \mathrm{CO}_{3}$ as a SOLUTION B in a beaker contained reservoir solution of $0.02 \mathrm{M} \mathrm{NaOH}$. The mixture of prepared NiLDHs mixed by mechanical stirrer (Figure 12). 


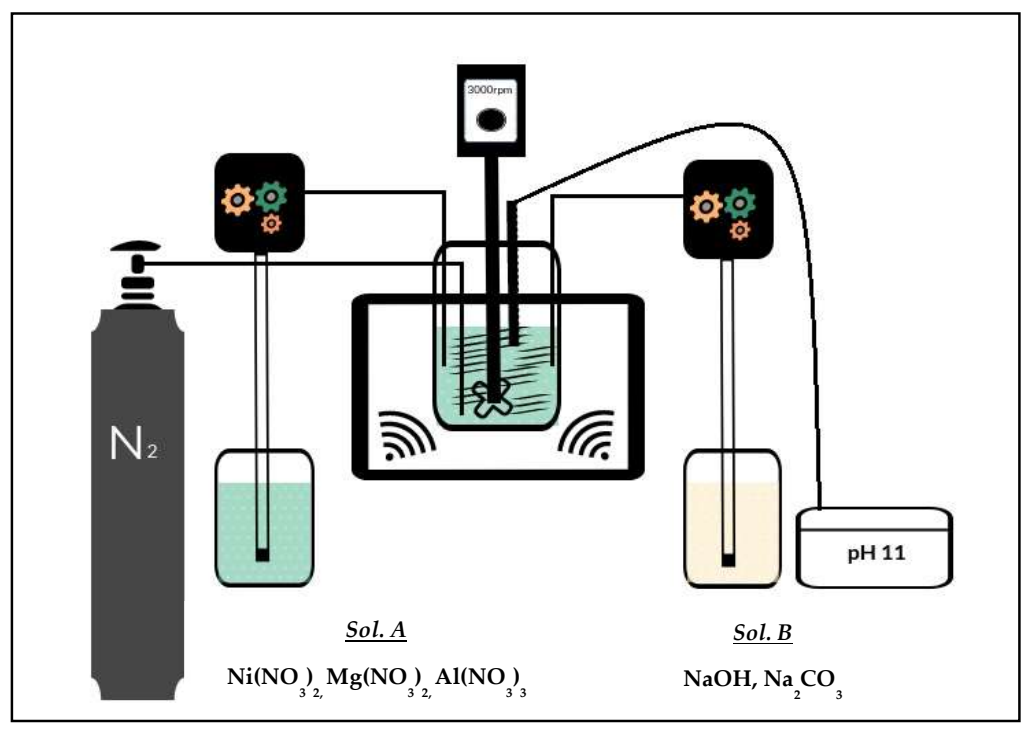

Figure 12. Schematic drawing of the co-precipitation for NiLDHs-Dr.

$\mathrm{pH}$ was fixed at 11 by controlling the flow rate of solutions $\mathrm{A}$ and $\mathrm{B}$. After the end of precipitation process, the mixture was washed until $\mathrm{pH}$ reached to 7 or showed no $\mathrm{Na}^{+}$ions were contained by ICP-AES. Then, the mixture was filtered, dried in oven at $80{ }^{\circ} \mathrm{C}$ for 20 hours and it was coded as 1NiLDHs-Dr, 1.5NiLDHs-Dr and 2NiLDHs-Dr depending to anticipated molar content of Ni.

\subsection{Preparation of reduced NiLDHs}

Hydrogen reduction of NiLDHs-Dr for different chemical compositions at temperature $200{ }^{\circ} \mathrm{C}$ were carried out in a U-shaped quartz reactor. The reduction of NiLDHs-Dr was occurred in $5 \% \mathrm{H}_{2} /$ $\mathrm{N}_{2}$ atmosphere with flow $90 \mathrm{ml} / \mathrm{min}$. for 3h using CHEMBET 3000, Quantachrome, USA. After reduction, the samples coded as 1NiLDHs-R200, 1.5NiLDHs-R200 and 2NiLDHs-R200. The chemical composition of $2 \mathrm{NiLDHs}$ reduced also under the same previous atmosphere and conditions at different temperature - 300 and $450^{\circ} \mathrm{C}$ - and coded as 2NiLDHs-R300 and 2NiLDHs-R450.

\subsection{Measurements and Characterization}

Determination of strength of basic sites in deferent ratio NiLDHs was done qualitatively by Hammett indicators [37]. $25 \mathrm{mg}$ of NiLDHs was shaking with $1 \mathrm{~mL}$ of Hammett indicator solution $0.1 \%$ in methanol and left to equilibrate $2 \mathrm{~h}$. The changing color of NiLDHs was then noted. The base strength is qualitatively determining as stronger than the weakest indicator which exhibits a color change and weaker than the strongest indicator which exhibits no color change. The Hammett indicators that listed in Table 7 were used. To determine the basicity for NiLDHs quantitatively, titration method was used with benzoic acid [37, 38]. $150 \mathrm{mg}$ of NiLDHs was stirred in $2 \mathrm{~mL}, 0.1$ $\mathrm{mg} / \mathrm{mL}$ of toluene solution of phenolphthalein for $30 \mathrm{~min}$ then titrated with $0.01 \mathrm{M}$ of toluene solution of benzoic acid. The total basicity was determined from molarity and the consumed volume of titrant. The leachable basicity [37] was also determined by shaking $500 \mathrm{mg}$ of NiLDHs in $50 \mathrm{~mL}$ water for $1 \mathrm{~h}$ at room temperature. After that, the NiLDHs was separated by centrifuge then $5 \mathrm{~mL}, 0.1 \mathrm{mg} / \mathrm{mL}$ of methanol solution of phenolphthalein was added to the filtrate then was titrated with $0.01 \mathrm{M}$ of methanol solution of benzoic acid.

Inductively Coupled Plasma Optical Emission Spectroscopy (ICP-OES) was performed using PerkinElmer Optima 7000 DV. ICP-OES data were used to determine the molecular formula of the samples. The better selected wavelengths were $309.271 \mathrm{~nm}$ for Al, $227.022 \mathrm{~nm}$ for $\mathrm{Ni}$ and $279.077 \mathrm{~nm}$ for $\mathrm{Mg}$. 
The X-ray photoelectron spectroscopy (XPS) measurements were carried out by using a SPECS $\mathrm{GmbH}$ X-ray photoelectron spectrometer. Prior to analysis, the samples were degassed under vacuum inside the load lock for $16 \mathrm{~h}$. The binding energy of the adventitious carbon (C 1s) line a 284.6 $\mathrm{eV}$ was used for calibration, and the positions of other peaks were corrected according to the position of the $C$ 1s signal.

Powder X-ray diffraction (XRD) measurements were carried out using a Bruker diffractometer (Bruker D8 advance target, Karlsruhe, Germany) at room temperature. The patterns were obtained using $\mathrm{Cu} \mathrm{K \alpha} 1$ and a monochromator $(\lambda=1.5405 \AA)$ at $40 \mathrm{kV}$ and $40 \mathrm{~mA}$, with $2 \theta$ varying between $2^{\circ}$ and $80^{\circ}$.X'Pert HighScore Plus software was used to analyze the spectra. The crystallite size of NiLDH was calculated using Scherrer equation:

$$
d(n m)=\frac{0.9 \times \lambda}{B \times \operatorname{Cos}(\theta)}
$$

where $d$ is the average crystallite size of the NiLDH under investigation, $\lambda$ is wavelength of the X-ray beam used, 0.9 is the Scherrer constant, B is the full width at half maximum (FWHM) of diffraction peak and $\theta$ is the diffraction angle.

Fourier transfer infrared (FTIR) spectroscopy in transmission mode was performed using a PerkinElmer UATR Two FT-IR spectrometer. The measurements were carried out in the wavenumber range $4000-400 \mathrm{~cm}^{-1}$ with $4 \mathrm{~cm}^{-1}$ resolution.

Thermogravimetric analysis (TGA) runs were carried out on TA instrument apparatus (model TGA-Q500). In each run 6-10 mg was placed in the TGA pan and heated to $800{ }^{\circ} \mathrm{C}$ at a heating rate of

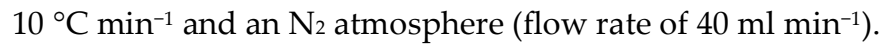

High resolution field emission (FEG quanta 250) scanning electron microscope (SEM) connected with Energy Dispersive X-Ray (EDX) detector which allows the chemistry of NiLDHs to be investigated on the sub-micron scale.

Texture properties of the prepared samples were determined from nitrogen adsorption/desorption Isotherms measurements at $77 \mathrm{~K}$ using a model NOVA3200e automated gas sorption system (Quantachrome, USA). Prior to the measurement, each sample was degassed for $6 \mathrm{~h}$ at $200{ }^{\circ} \mathrm{C}$. The specific surface area, SBET, was calculated by applying the Brunauer-Emmett-Teller (BET) equation [39]. Pore size distribution over the mesopore range was generated by the BarrettJoyner-Halenda (BJH) [40] analysis of the desorption branches, and values of the average pore size were calculated.

Gas chromatography analyses were done by using BRUKER SCION 456-GC-MS with BR-1 capillary column ( $30 \mathrm{~m}, 0.25 \mathrm{~mm}$ ID, $0.25 \mathrm{um}$ ).

Table 7. List of Hammett indicators that were used to determine basic sites.

\begin{tabular}{rlrrrc}
\hline \multirow{2}{*}{ No. } & \multirow{2}{*}{ Hammett Indicators } & \multirow{2}{*}{ pKa } & \multirow{2}{*}{ pH Range } & \multicolumn{2}{c}{ Changing Color } \\
\cline { 5 - 6 } & & & & Acidic & Basic \\
\hline 1 & Thymol blue (First change) & 1.5 & $1.2-2.8$ & Red & Yellow \\
2 & Methyl yellow & 3.3 & $2.9-4.0$ & Red & Yellow \\
3 & Methyl red & 5.1 & $4.2-6.2$ & Red & Yellow \\
4 & Bromothymol blue & 7.0 & $6.0-7.6$ & Yellow & Blue \\
5 & Thymol blue (Second change) & 8.9 & $8.0-9.6$ & Yellow & Blue \\
6 & Phenolphthalein & 9.4 & $8.3-10.0$ & Colorless & Pink \\
7 & Tropaeolin-0 & 11.9 & $11.1-12.7$ & Yellow & Orange \\
\hline
\end{tabular}

\subsection{Experimental Procedure for Suzuki reaction}

4-tolylboronic acid ( $1.5 \mathrm{mmol}, 204 \mathrm{mg})$, potassium phosphate (2 mmol, $533 \mathrm{mg})$, catalyst ( $50 \mathrm{mg}$ ) and 1,4-dioxane/water $(5: 1,2 \mathrm{~mL})$ were put in a Teflon vessel. After iodobenzene $(1 \mathrm{mmol}, 111 \mu \mathrm{L})$ was added, the vessel was sealed with a Teflon cover and put into the microwave oven (Milestone ETHOS 1). The reaction mixture was rapidly heated to $200{ }^{\circ} \mathrm{C}$ by setting the microwave irradiation to $800 \mathrm{~W}$. After the reaction reached $200^{\circ} \mathrm{C}$, taking $10 \mathrm{~min}$, it was held for $60 \mathrm{~min}$. After the reaction mixture was cooled to room temperature, it was washed with Ethanol, filtered by passing through 
Celite and dried from water moisture over $\mathrm{Mg}_{2} \mathrm{SO}_{4}$. Analyzing the filtrate by $\mathrm{GC}-\mathrm{MS}$ to determine the yield of the desired product using biphenyl as internal standard $\left(1 \times 10^{-2} \mathrm{M}\right.$ in Ethanol).

\section{Conclusion}

In this study, Ni-layered double hydroxides (NiLDHs) were prepared by co-precipitation method under ultrasonic irradiation. Isomorphic substitution of $\mathrm{Mg}^{2+}$ by $\mathrm{Ni}^{2+}$ ions was proved by XRD. All the investigated NiLDHs catalysts exhibited capable catalytic activity towards Suzuki carbon-carbon homocoupling reaction. The dried as-synthesized 2NiLDHs-Dr was highly efficient comparing to other synthesized/treated catalysts. The results obtained claimed that the catalytic efficacy was correlated to Ni-content more than the basicity of the catalysts. Different aryl halide and boronic acid derivatives were used in catalytic activity test and coupling iodobenzene with 4-methyl boronic acid gave the highest percent yield. The reusability test of the catalyst showed a pronounced decay in catalytic activity after first use as a result of Ni leaching, loss of catalyst by filtration and active site contamination. Pd-free catalyst with high catalytic efficacy towards Suzuki C-C homocoupling was attained and vital enhancement for better re-usability is currently under investigation.

Physical and spectral data of the titled compounds (Supplementary Materials). 4-methylbiphenyl

1H NMR (400 MHz, $\left.\mathrm{CDCl}_{3}\right) \delta 7.56-7.58(\mathrm{q}, 2 \mathrm{H}), 7.46-7.50(\mathrm{t}, 2 \mathrm{H}), 7.39-7.43(\mathrm{t}, 2 \mathrm{H}), 7.29-7.33(\mathrm{t}$, 1H), $7.21-7.25$ (t, 2H), 2.39 (s, 3H)); 13C NMR (400 MHz, $\left.\mathrm{CDCl}_{3}\right) \delta$ 141.21, 138.40, 137.05, 129.51, $129.47,128.74,127.00,77.38,77.07,76.75,21.12$.

\section{References}

1. Diez, A.S., et al., Suzuki-Miyaura cross-coupling of aryl iodides and phenylboronic acid over palladium-free $\mathrm{CeO} 2$ catalysts. Applied Catalysis A: General, 2014. 482: p. 24-30.

2. Li, Y., et al., Gold nanoparticles-graphene hybrids as active catalysts for Suzuki reaction. Materials Research Bulletin, 2010. 45(10): p. 1413-1418.

3. Lee, E.-K., et al., Platinum single atoms dispersed on carbon nanotubes as reusable catalyst for Suzuki coupling reaction. Journal of Catalysis, 2017. 352: p. 388-393.

4. Mao, J., et al., Highly efficient copper(0)-catalyzed Suzuki-Miyaura cross-coupling reactions in reusable PEG-400. Tetrahedron, 2008. 64(18): p. 3905-3911.

5. Lipshutz, B.H., J.A. Sclafani, and P.A. Blomgren, Biaryls via Suzuki Cross-Couplings Catalyzed by Nickel on Charcoal. Tetrahedron, 2000. 56(15): p. 2139-2144.

6. Lipshutz, B.H., T. Butler, and E. Swift, C-C Bond Formation Catalyzed Heterogeneously by Nickelon-Graphite (Ni/Cg). Organic Letters, 2008. 10(5): p. 697-700.

7. You, E., P. Li, and L. Wang, Nickel(0)/Tetra-n-butylammonium Bromide (TBAB) Catalyzed Suzuki-Miyaura Reaction. Synthesis, 2006. 2006(09): p. 1465-1469.

8. Dequirez, G., et al., Microwave-Assisted Suzuki-Miyaura Cross Coupling using Nickel as Catalyst to Rapidly Access to 3-Arylazetidine. ChemistrySelect, 2017. 2(28): p. 8841-8846.

9. Guo, Y., D.J. Young, and T.S. Andy Hor, Palladium-free Suzuki-Miyaura cross-coupling at elevated pressures. Tetrahedron Letters, 2008. 49(39): p. 5620-5621.

10. E., L.N. and M. Maria, Transition-Metal-Free Suzuki-Type Coupling Reactions. Angewandte Chemie, 2003. 115(12): p. 1445-1447.

11. Arvela, R.K., et al., A Reassessment of the Transition-Metal Free Suzuki-Type Coupling Methodology. The Journal of Organic Chemistry, 2005. 70(1): p. 161-168. 
12. Yan, J., W. Hu, and G. Rao, A novel and efficient coupling reaction of sodium tetraphenylborate with hypervalent iodonium salts. Synthesis, 2006. 2006(06): p. 943-945.

13. Yan, J., W. Hu, and W. Zhou, Rapid Microwave-Promoted Catalyst-and Solvent-Free Suzuki-Type Coupling Reaction. Synthetic communications, 2006. 36(15): p. 2097-2102.

14. Dumbre, D., V.R. Choudhary, and P.R. Selvakannan, Cu-Fe layered double hydroxide derived mixed metal oxide: Environmentally benign catalyst for Ullmann coupling of aryl halides. Polyhedron, 2016.

15. Choudary, B.M.R., Moumita Roy, Sarabindu Kantam, M. Lakshmi, Layered double hydroxides supported nanoplatinum catalyst for Suzuki coupling of aryl alides. Journal of Molecular Catalysis A: Chemical, 2005. 241(1-2): p. 215-218.

16. Kantam, M.L.R., Sarabindu Roy, Moumita Sreedhar, Bojja Choudary, B. M. De, Rajib Lal, Layered double hydroxides supported rhodium(0): An efficient and reusable catalyst for Heck, Suzuki, and Stille reactions of haloarenes. Journal of Molecular Catalysis A: Chemical, 2007. 273(1-2): p. 26-31.

17. Narasimharao, K., et al., Microwave assisted efficient protocol for the classic Ullmann homocoupling reaction using $\mathrm{Cu}-\mathrm{Mg}-\mathrm{Al}$ hydrotalcite catalysts. Journal of Molecular Catalysis A: Chemical, 2013. 379: p. 152-162.

18. Abdellattif, M. and M. Mokhtar, MgAl-Layered Double Hydroxide Solid Base Catalysts for Henry Reaction: A Green Protocol. Catalysts, 2018. 8(4): p. 133.

19. Celaya-Sanfiz, A., et al., Self-condensation of acetone over $\mathrm{Mg}-\mathrm{Al}$ layered double hydroxide supported on multi-walled carbon nanotube catalysts. Journal of Molecular Catalysis A: Chemical, 2015. 398: p. 50-57.

20. Ahmed, N.S., et al., Graphene-oxide-supported CuAl and CoAl layered double hydroxides as enhanced catalysts for carbon-carbon coupling via Ullmann reaction. Journal of Solid State Chemistry, 2017. 246: p. 130-137.

21. Evans, D.G. and R.C.T. Slade, Structural Aspects of Layered Double Hydroxides, in Layered Double Hydroxides, X. Duan and D.G. Evans, Editors. 2006, Springer Berlin Heidelberg: Berlin, Heidelberg. p. 1-87.

22. Yu, X., et al., Hydrogen Evolution Reaction in Alkaline Media: Alpha- or Beta-Nickel Hydroxide on the Surface of Platinum? ACS Energy Letters, 2018. 3(1): p. 237-244.

23. Ge, X., et al., Anomalous self-reduction of layered double hydroxide ( $\mathrm{LDH})$ : from $\alpha$-Ni(OH)2 to hexagonal close packing (HCP) Ni/NiO by annealing without a reductant. Chemical Communications, 2015. 51(6): p. 1004-1007.

24. Ma, R., et al., Molecular-Scale Heteroassembly of Redoxable Hydroxide Nanosheets and Conductive Graphene into Superlattice Composites for High-Performance Supercapacitors. Advanced Materials, 2014. 26(24): p. 4173-4178.

25. Mokhtar, M., et al., Thermal decomposition, gas phase hydration and liquid phase reconstruction in the system $\mathrm{Mg} / \mathrm{Al}$ hydrotalcite/mixed oxide: A comparative study. Applied Clay Science, 2010. 50(2): p. 176-181.

26. Rives, V. and S. Kannan, Layered double hydroxides with the hydrotalcite-type structure containing $\mathrm{Cu} 2+, \mathrm{Ni2}+$ and Al3+. Journal of Materials Chemistry, 2000. 10(2): p. 489-495.

27. Rouquerol, J., et al., Recommendations for the characterization of porous solids (Technical Report), in Pure and Applied Chemistry. 1994. p. 1739. 
28. Sing, K.S., Reporting physisorption data for gas/solid systems with special reference to the determination of surface area and porosity (Recommendations 1984). Pure and applied chemistry, 1985. 57(4): p. 603-619.

29. Cross-coupling reactions: A practical guide, in Topics in Current Chemistry, N. Miyaur, Editor. 2002, Springer-Verlag Berlin Heidelberg: New York. p. 11-59.

30. Boyapati M. Choudary, S.M., Naidu S. Chowdari, Mannepalli L. Kantam, Bojja Sreedhar, Layered Double Hydroxide Supported Nanopalladium Catalyst for Heck-, Suzuki-, Sonogashira-, and Stille-Type Coupling Reactions of Chloroarenes. American Chemical Society, 2002. 124: p. 1412714136.

31. Zheng, Z., et al., Monodisperse noble metal nanoparticles stabilized in SBA-15: Synthesis, characterization and application in microwave-assisted Suzuki-Miyaura coupling reaction. Journal of Catalysis, 2010. 270(2): p. 268-274.

32. Chen, C. and L.-M. Yang, Nickel (II)-aryl complexes as catalysts for the Suzuki cross-coupling reaction of chloroarenes and arylboronic acids. Tetrahedron letters, 2007. 48(13): p. 2427-2430.

33. Navidi, M., N. Rezaei, and B. Movassagh, Palladium(II)-Schiff base complex supported on multiwalled carbon nanotubes: A heterogeneous and reusable catalyst in the Suzuki-Miyaura and copperfree Sonogashira-Hagihara reactions. Journal of Organometallic Chemistry, 2013. 743: p. 63-69.

34. Kabalka, G.W., et al., Solventless Suzuki coupling reactions on palladium-doped potassium fluoride alumina. Synthesis, 2003. 2003(02): p. 0217-0222.

35. Q3D Elemental Impurities Guidance for Industry. Food and Drug Administration, 2015.

36. Fang, P.P., et al., Au-Pd core-shell nanoparticles catalyze Suzuki-Miyaura reactions in water through Pd leaching. Angewandte Chemie, 2011. 123(51): p. 12392-12396.

37. Fraile, J.M., et al., The influence of alkaline metals on the strong basicity of $M g-A l$ mixed oxides: The case of transesterification reactions. Applied Catalysis A: General, 2009. 364(1): p. 87-94.

38. van Laar, F.M.P.R., et al., Generation of Singlet Molecular Oxygen from H2O2 with MolybdateExchanged Layered Double Hydroxides: Effects of Catalyst Composition and Reaction Conditions. Journal of Catalysis, 2001. 197(1): p. 139-150.

39. Brunauer, S., P.H. Emmett, and E. Teller, Adsorption of Gases in Multimolecular Layers. Journal of the American Chemical Society, 1938. 60(2): p. 309-319.

40. Barrett, E.P., L.G. Joyner, and P.P. Halenda, The Determination of Pore Volume and Area Distributions in Porous Substances. I. Computations from Nitrogen Isotherms. Journal of the American Chemical Society, 1951. 73(1): p. 373-380. 